This document is the accepted manuscript version of the following article:

Descombes, P., Vittoz, P., Guisan, A., \& Pellissier, L. (2017). Uneven rate of plant turnover along elevation in grasslands. Alpine Botany, $127(1), 53-63$. https://doi .org/10.1007/s00035-016-0173-7

\title{
5 Uneven rate of plant turnover along elevation in grasslands
}

7 Patrice Descombes ${ }^{1,2 *}$, Pascal Vittoz ${ }^{3}$, Antoine Guisan ${ }^{3,4}$, Loïc Pellissier ${ }^{1,2}$

${ }^{1}$ Landscape Ecology, Institute of Terrestrial Ecosystems, ETH Zürich, CH-8092 Zürich, Switzerland

${ }^{2}$ Swiss Federal Research Institute WSL, CH-8903 Birmensdorf, Switzerland

${ }^{3}$ University of Lausanne, Institute of Earth Surface Dynamics, Géopolis, CH-1015 Lausanne, Switzerland

${ }^{4}$ University of Lausanne, Department of Ecology and Evolution, Biophore, CH-1015

Lausanne, Switzerland

*Corresponding author: Patrice Descombes, patrice.descombes@wsl.ch

\section{Keyword}

Plant communities; nestedness; Swiss Alps; species diversity; phylogenetic turnover

\section{Acknowledgements}

We thank all the people involved in collecting the vegetation data over the years and two anonymous reviewers for their constructive comments on the manuscript. This project was supported by the Swiss National Science Foundation (SNSF) grant n³1003A-162604 and grant $n^{\circ} 31003 \mathrm{~A}-1528661$. 
28 Authors contributions: PD and LP designed the study. LP, PV, AG and colleagues collected 29 the data. PD performed the statistical analyses. PD and LP wrote the first draft of the 30 manuscript and, PV and AG contributed to the writing. 


\section{Abstract}

Plant taxonomic and phylogenetic composition of assemblages are known to shift along environmental gradients, but whether the rate of species turnover is regular or not (e.g., accelerations in particular sections of the gradient) remains poorly documented. Understanding how rates of assemblage turnover vary along gradients is crucial to forecast where climate change could promote the fastest changes within extant communities. Here we analysed turnover rates of plant assemblages along a $2500 \mathrm{~m}$ elevation gradient in the Swiss Western Alps. We found a peak of turnover rate between $1800 \mathrm{~m}$ and $2200 \mathrm{~m}$ indicating an acceleration of grassland compositional changes at the transition between subalpine and alpine belts. In parallel, we found a peak in phylogenetic turnover rate in Poales between 1700 $\mathrm{m}$ and $1900 \mathrm{~m}$ and Super-Rosids between $1900 \mathrm{~m}$ and $2300 \mathrm{~m}$. Our results suggest that changes in abiotic or biotic conditions near the human-modified treeline constitute a strong barrier for many grassland plant species, which share analogous elevation range limits. We propose that this vegetation zone of high ecological transitions over short geographical distances should show the fastest community responses to climate change from the breakdown of barrier across ecotones.

\section{Introduction}

Since species survive and reproduce within bounded abiotic conditions (Hutchinson 1957; Soberón 2007), the composition of species assemblages changes along environmental gradients. Clines in temperature or moisture are generally associated with strong species compositional changes, such as in plants (Gentry 1988; Pellissier et al. 2010; de Bello et al. 2013), animals (Sanders 2002; Graham et al. 2009; Longino and Colwell 2011; Pellissier et al. 2012) and even microorganisms (Pellissier et al. 2014a). However, few studies so far investigated the rate of assemblage turnover along environmental gradients (Mena and Vázquez-Domínguez 2005; Bach et al. 2007; Jankowski et al. 2009; Jankowski et al. 2013). If all species show idiosyncratic response to abiotic conditions, a constant rate of compositional turnover is expected along the entire environmental gradient (Gleason 1926; Bach et al. 2007). In contrast, if a large proportion of species shares similar environmental limits, referred as "range boundary clumping" (Clements 1916; Leibold and Mikkelson 2002), a peak in the turnover component of beta-diversity would be expected in this section of the gradient (Mena and Vázquez-Domínguez 2005). 
Elevation gradients are among the most studied environmental clines in ecology since they provide large variations in abiotic conditions over very short distances (Körner 2007). In the Alps and other mountain ranges in temperate climate, the climate shifts toward more stressful conditions for plant growth with increasing elevation (Körner 2003) and clines in species alpha- and beta-diversity can be observed (Körner 2000; Dubuis et al. 2011; Pellissier et al. 2013a). Species richness decreases (Körner 2000; Vittoz et al. 2010) and lowland species are replaced by high elevation specialists (Körner 2000; Theurillat et al. 2003). Gradients in environmental conditions along elevation can also be confounded with change in human land uses and disturbances, and in the intensity of biotic processes, especially around the treeline (Pottier et al. 2013). Yet, the rate of compositional changes along elevation remains poorly studied (Odland and Birks 1999; Jankowski et al. 2013). Jankowski et al. (2013) investigated compositional changes of trees and birds in tropical mountains of the Peruvian Andes and showed distinct peaks in plant and bird turnover rates along elevation. At a functional level, Ndiribe et al. (2013b) demonstrated the importance of climate and land-use factors in shaping patterns of functional and phylogenetic beta-diversity, and Pellissier et al. (2010) highlighted that dominant functional traits expressed in communities in the Swiss Alps change more rapidly around the treeline. Repeated beta-diversity comparisons between pairs of plots experiencing a small difference in elevation allows us to evaluate the evenness of the nestedness and turnover components of beta-diversity along elevation.

Complementing measures of taxonomic beta-diversity, phylogenetic beta-diversity provides additional insights into the mechanisms underlying diversity patterns along environmental gradients by considering phylogenetic relatedness among species (Graham and Fine 2008; Pellissier et al. 2013b). Phylogenetic community ecology is tightly linked to the concept of niche conservatism, the tendency of closely related species to retain the same environmental niche (Wiens et al. 2010). Phylogenetic turnover of assemblages along environmental gradients is expected to reflect niche-related processes, especially environmental filtering of lineages (Graham and Fine 2008). Phylogenetic diversity patterns have been observed to change along elevation (Culmsee and Leuschner 2013; Ndiribe et al. 2013a; Pellissier et al. 2013b), but the absence of relationships were also documented in other studies (Bryant et al. 2008; Chalmandrier et al. 2015). Large phylogenetic distances associated to low trait conservatism between species in assemblages can blur ecological signals (Kembel and Hubbell 2006; Godoy et al. 2014). Thus, focusing on patterns within specific clades might provide more detailed information. If niche boundaries are phylogenetically conserved, or clumped in particular clades, the rate of phylogenetic turnover 
along elevation should not be constant but present irregularities in sections of the elevation gradient (Ndiribe et al. 2013a).

Taxonomic beta-diversity variation along environmental gradients can be further decomposed into a turnover and a nestedness component (Baselga 2010). Nestedness of species assemblages occurs when the species composition of sites with smaller numbers of species are subsets of the composition at richer sites (Wright and Reeves 1992; Ulrich and Gotelli 2007), and reflects species loss as a consequence of processes promoting the disaggregation of assemblages into its subsets (Gaston et al. 2000). In contrast, assemblage turnover implies the replacement of some species by others across community pairs, and results predominantly from a shift in environmental conditions (Qian et al. 2005). Decomposing beta-diversity into turnover and nestedness components provides complementary information on the processes shaping the assembly of communities (Baselga and Leprieur 2015).

Here, we investigate the gamma- and alpha-diversity, and the turnover and nestedness components of beta-diversity of plant communities in grasslands along a 2500 meters elevation gradient in the Western Swiss Alps with a special emphasis on the evenness of the turnover rate. We computed beta-diversity of pairs of plots separated by an elevation smaller than 20 meters and decomposed it into turnover and nestedness components (Baselga 2010). Using a species-level phylogeny of the regional flora, we further investigated phylogenetic turnover of Poales, Super-Asterids and Super-Rosids clades along elevation. In the case of idiosyncratic response of species to shifting environmental conditions along the elevation gradient, we should observe a flat relationship between turnover rate and elevation. In contrast, if species share similar range limits, a higher turnover rate should be observed in portions of the gradient. Documenting turnover rates along elevation gradients is particularly relevant in the context of climate change. Sections of the gradient with higher turnover rate indicate the presence of a strong barrier across different ecosystems, which might be lifted by climate change.

\section{Methods}

Study area and data collection 
The study area, covering approximately $700 \mathrm{~km}^{2}$, is located in the Western Alps of Switzerland (canton de Vaud) and exhibits an elevational gradient ranging from $375 \mathrm{~m}$ to $3200 \mathrm{~m}$ with a soil parent material that is mainly calcareous $\left(46^{\circ} 10^{\prime}-46^{\circ} 30^{\prime} \mathrm{N} ; 6^{\circ} 50^{\prime}-7^{\circ} 10^{\prime} \mathrm{E}\right.$; Fig. 1). The region has a temperate climate with mean annual temperature between $8{ }^{\circ} \mathrm{C}$ at $375 \mathrm{~m}$ and $-5^{\circ} \mathrm{C}$ at $3200 \mathrm{~m}$ and with annual sum of precipitation between $1200 \mathrm{~mm}$ and 2600 mm (Bouët 1985). Below the treeline (i.e. $1900 \mathrm{~m}$; lowered by a few 100 meters through centuries of human activities; Gehrig-Fasel et al. 2007), most of the open vegetation areas are used for grazing and/or mowing, often with regular fertilization, whereas the areas in alpine belt are occupied by alpine grasslands and glaciers with much lower levels of human disturbance, except cattle grazing in summer on the most accessible areas. The species data have been collected in open and non-woody vegetation areas only (i.e. grasslands, meadows, rocks and screes; see Fig. S1 to see how open areas and selected plots are distributed along the elevation gradient) using a balanced random stratified sampling design (Hirzel and Guisan 2002) relying on slope, elevation and aspect (see Fig. S2 to see how the selected plots are distributed in the ecological space). Since slope, elevation and aspect are proxies for contrasted ecological conditions, this design allows us to collect data from the full range of vegetation types present along the elevation gradient. The vegetation sampling includes 912 sites surveyed exhaustively on 2 × 2 m squares across the whole gradient between 2002 and 2009 (for more details see Dubuis et al. 2011) and which had similar topography. Species cover was visually estimated according to a 7-level scale.

Alpha- and gamma-diversity

To investigate how the local species pools vary along elevation gradient, we computed the total number of species encountered in sampled plant communities within $20 \mathrm{~m}$ elevation bands centred on each $10 \mathrm{~m}$ elevation steps. This represents the local gamma-diversity defined for each elevation section. In this study, we only used elevation as ecological gradient (see Körner 2007) since this gradient is highly correlated to abiotic factors such as degreedays (Spearman's correlation: $r=-0.997$; Fig. S2) or precipitation (Spearman's correlation: $r$ $=0.959$; Fig. S2), and also associated with shifts in biotic conditions such as reduced competition at higher elevation (e.g. Michalet et al. 2006; Michalet et al. 2015), a decrease in herbivore pressure (e.g. Reynolds and Crossley 1997; Garibaldi et al. 2011; Pellissier et al. $2014 b$ ) or a gradient of land use by humans (see above). 
In addition, within each of the $20 \mathrm{~m}$ elevation sections, we computed the mean number of species found in communities as a measure of local average alpha-diversity in each elevation band. Comparing alpha- and gamma-diversity and their deviation along elevation, a measure of beta-diversity (Tuomisto 2010), provide information on the intensity of environmental and human mediated filtering processes within each elevation band. The range of $20 \mathrm{~m}$ was selected because it constitutes a good compromise between resolution of the elevation bands and number of possible comparisons between pairs of vegetation plots. However, to ensure that our conclusions were non sensitive to the choice of threshold, we also ran the analyses with a range of $10 \mathrm{~m}$ and a range of $50 \mathrm{~m}$. Because land use might influence plant alpha- and gamma-diversity patterns (e.g. Fischer et al. 2008; Niedrist et al. 2009), we also related number of open areas (see Fig. S1) and diversity of vegetation types (see Fig. S3) to the alpha- and gamma-diversity within each of the 20 m elevation bands. Plots were grouped with a hierarchical clustering and the groups were attributed to a vegetation type, according to the classification of Delarze and Gonseth (2008), on the basis of their respective differential species.

\section{Community taxonomic turnover and nestedness of beta-diversity}

We computed beta-diversity of all plant species, Poales (i.e. Cyperaceae, Juncaceae and Poaceae), Super-Asterids (i.e. Apiales, Asterales, Caryophyllales, Dipsacales, Ericales, Gentianales, Lamiales and Santalales) and Super-Rosids (i.e. Brassicales, Celastrales, Fabales, Geraniales, Malpighiales, Malvales, Rosales and Saxifragales) between all pairs of communities with an elevation difference lower than $20 \mathrm{~m}$ and partitioned the total betadiversity (Jaccard dissimilarity index, $\beta_{\mathrm{jac}}$ ) into turnover (Turnover component of Jaccard dissimilarity, $\beta_{\mathrm{jtu}}$ ) and nestedness-resultant dissimilarity (Nestedness-resultant component of Jaccard dissimilarity, $\beta_{\text {jne}}$ ) by using the package "betapart" (Baselga 2012; Baselga and Orme 2012) in R (R Development Core Team, www.R-project.org ). $\beta_{\mathrm{jtu}}$ and $\beta_{\mathrm{jne}}$ vary between 0 and 1 , where high values indicate greater dissimilarity in species composition and low values indicate greater proportion of shared species. In the absence of nestedness (i.e. species between pairs of communities are completely different), $\beta_{\mathrm{jtu}}$ is equal to $\beta_{\mathrm{jac}}$ and equal to 1 . The difference between $\beta_{\mathrm{jtu}}$ and $\beta_{\mathrm{jac}}$ is a measure of the nestedness component of beta-diversity. In the absence of turnover (i.e. species of a community are a subset of a richer community), $\beta_{\mathrm{jne}}$ is equal to $\beta_{\mathrm{jac}}$ and is influenced by differences in species richness. We related the $\beta_{\mathrm{jtu}}$ and $\beta_{\mathrm{jne}}$ values to the mean elevation of each pair of plots using a linear model including both a linear 
and a quadratic term. Any deviation from an intercept-only model, either with a linear or nonlinear slope, would indicate a non-constant turnover and nestedness rate along elevation. We also investigated how the spatial distance between pairs of plots varies between elevation bands along the elevation gradient by relating the horizontal distance separating each pair of plots with their mean elevation and their taxonomic turnover $\left(\beta_{\mathrm{jtu}}\right)$. Because land use might influence plant beta-diversity patterns (Ndiribe et al. 2013b), we also related elevation and habitat variables (i.e. number of open areas, diversity of vegetation types) to the mean taxonomic turnover $\left(\beta_{\mathrm{jtu}}\right)$ within $20 \mathrm{~m}$ elevation bands by using an ordinary least squares regression (OLS) model and quantified the relative importance of elevation vs. habitat variables for explaining beta-diversity variation with a variance partitioning analyses (see Appendix S1 for methodological details on the OLS models and variable partition analyses). Finally, we extracted the elevation minima and maxima of each plant species from the 912 plots. We related these range limits to the elevation gradient in order to explain how range boundaries could influence dissimilarities in species composition.

\section{Community phylogenetic turnover of beta-diversity}

We tested the phylogenetic signal in species distribution along the elevation gradient (the median elevation at which the species occurred), by pruning from a published phylogeny of the 231 most frequent and abundant plant species in our study area (Ndiribe et al. 2013a). We calculated Blomberg's K statistic with the "phylosignal" function as implemented in the “picante" R package (Blomberg et al. 2003; Kembel et al. 2010), as our measure of phylogenetic signal. We calculated Blomberg's K across all species and in three angiosperm clades: Poales, Super-Asteridsand Super-Rosids. Blomberg's K statistic compares the observed distribution of the trait values to expectations under a Brownian motion model of trait evolution. $\mathrm{K}$ values close to 1 indicate trait evolution consistent with a Brownian motion model of evolution, while $\mathrm{K}$ values close to 0 indicate a random distribution of trait values with respect to the phylogeny (Blomberg et al. 2003). We tested the significance of this test by comparing the observed $\mathrm{K}$ value to a null distribution generated by comparing 999 randomisations of trait values across the tips of the phylogenetic tree (Kembel et al. 2010).

We computed phylogenetic turnover of beta-diversity of all plant species, Poales, Super-Asterids and Super-Rosids between pairs of plots with an elevation difference lower than $20 \mathrm{~m}$, using the mean pairwise distance (MPD) implemented in the "comdist" function in 
the "picante" R package (Kembel et al. 2010). We related the mean elevation of each pair of plots with their phylogenetic turnover value and tested for the existence of shifts in rates of phylogenetic turnover using a linear model including quadratic terms. In order to visualize the contribution of families to communities along elevation, we calculated the proportion of species occurrences and the proportion of species cover of the dominant plant clades of Poales, Super-Asterids and Super-Rosids (i.e. Poaceae, Cyperaceae, Asteraceae, Fabaceae, Apiaceae, Saxifragaceae) for $200 \mathrm{~m}$ elevation bands.

\section{Results}

Alpha- and gamma-diversity

We found that the gamma-diversity within the 20-meters elevation bands showed a hump-shaped curve, with a peak between 1500 and 1900 m (Fig. 2a). Similarly, the mean alpha-diversity of communities within each elevation band showed a hump-shaped curve, but with a peak between 1100 and 1500 m (Fig. 2a). We observed a strong relationship between the gamma- and the mean alpha-diversity (Spearman's correlation: $r=0.632$ ), indicating that a larger gamma-diversity is associated with a higher mean alpha-diversity of communities, but the relationship showed higher discrepancies in some section of the gradient (Fig. 2a).

Differences between gamma- and mean alpha-diversities are overall larger at lower elevation, but with a peak around 1400-2100 m (maximum difference: 222 at $1820 \mathrm{~m}$ ). Note that the difference between gamma and alpha diversity in elevation bands of $20 \mathrm{~m}$ is another measure of beta-diversity (Tuomisto 2010), and showed only weak correlation with the turnover component of beta diversity calculated between pairs of plots with less than $20 \mathrm{~m}$ of difference in elevation (Spearman's correlation: $r=0.212$ ). Finally, we also observed a strong relationship between the gamma-diversity and the number of open areas (Spearman's correlation: $r=0.750)$ and the diversity of vegetation types $(r=0.786)$, indicating that larger open areas and areas with diverse vegetation types sustain higher gamma-diversity. The relationships with alpha-diversity were weaker for number of open areas $(r=0.585)$ and the diversity of vegetation types $(r=0.285)$.

\section{Community taxonomic turnover and nestedness of beta-diversity}


Overall, beta-diversity between pairs of plots along elevation is mainly generated by

255

256

257

258

259

260

261

262

263

264

265

266

267

268

269

270

271

272

273

274

275

276

277

278

279

280

281

282

283

284

285

286 species turnover ( $\beta_{\mathrm{jtu}}$; mean: 0.80, sd: 0.17; Fig. $2 \mathrm{~b}$ ), while the contribution of nestedness to

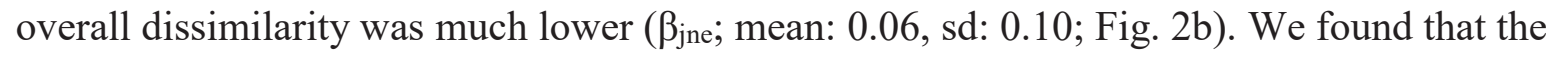
turnover $\left(\beta_{\mathrm{jtu}}\right)$ and nestedness $\left(\beta_{\mathrm{jne}}\right)$ components of beta-diversity were uneven along elevation $\left(\beta_{\mathrm{jtu}}\right.$ : linear $\mathrm{s}=4.8^{*} 10^{-4}$, quadratic $\mathrm{s}=-1.2^{*} 10^{-7}, \beta_{\text {jne }}$ : linear $\mathrm{s}=-2.6^{*} 10^{-4}$, quadratic $\mathrm{s}=7.9^{*} 10^{-8}$;

Fig. 2b). Including quadratic terms improved the models for turnover (AIC difference: -229.8) and nestedness (AIC difference: -260.7) supporting the existence of a hump-shaped relationship. The rate of community turnover was highest (greatest dissimilarity in proportion of unshared species) in the elevation section between 1800 and $2200 \mathrm{~m}$, while elevation ranges with the highest nestedness (greatest dissimilarity in proportion of shared species) were below $1200 \mathrm{~m}$ and above $2200 \mathrm{~m}$. We found a weak correlation between the Euclidian geographic distance separating pairs of plots with their mean elevation (Spearman's correlation: $r=-0.232)$ and with their taxonomic turnover $\left(\beta_{j t u}\right.$; Spearman's correlation: $r=$ 0.080), suggesting that shift in spatial distance along elevation does not explain the observed pattern of beta-diversity. We also found a weak relationship between mean beta-diversity $\left(\beta_{\mathrm{jtu}}\right)$ and the number of open areas (Spearman's correlation: $\left.r=0.363\right)$, alpha-diversity $(r=-$ $0.231)$ and gamma-diversity $(r=0.165)$ in elevation bands of $20 \mathrm{~m}$ along the elevation gradient. Elevation was the only significant parameter in the model (OLS model: estimate $=$ $0.460, \mathrm{t}$-value $=4.093, \mathrm{p}$-value $<0.001)$ explaining the variation in taxonomic turnover $\left(\beta_{\mathrm{jtu}}\right)$. When partitioning the explained variance of mean beta-diversity $\left(R^{2}=0.21\right)$ among elevation and habitat variables (i.e. number of open areas and diversity of vegetation types) in the OLS model, elevation displayed the strongest independent effect, with a higher independent proportion of explained variance $(11.7 \%)$ than habitat variables $(0.0 \%)$.

The turnover $\left(\beta_{\mathrm{jtu}}\right)$ component of beta-diversity was also uneven along elevation for Poales $\left(\beta_{\mathrm{jtu}}\right.$ : linear $\mathrm{s}=6.7^{*} 10^{-4}$, quadratic $\mathrm{s}=-1.8^{*} 10^{-7}$; Fig. $\left.3 \mathrm{a}\right)$, Super-Rosids $\left(\beta_{\mathrm{jtu}}\right.$ : linear $\mathrm{s}=$

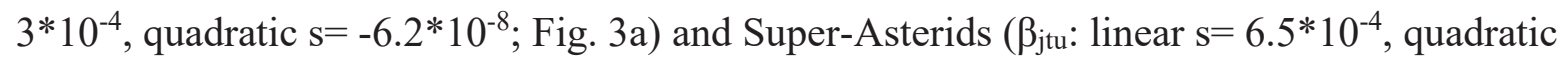
$\mathrm{s}=-1.9^{*} 10^{-7}$; Fig. 3a). Including quadratic terms improved the models for Poales (AIC difference: -154.9), Super-Rosids (AIC difference: -10.8) and Super-Asterids (AIC difference: -292), supporting the existence of a hump-shaped relationship. However, Super-Rosids show a weaker hump-shaped relationship than Poales and Super-Asterids (Fig. 3a). The rate of community turnover was highest in the elevation section between 1700 and $2000 \mathrm{~m}$ for Poales, between 2000 and $2400 \mathrm{~m}$ for Super-Rosids and between 1600 and $1900 \mathrm{~m}$ for SuperAsterids (Fig. 3a). 
The distribution of the species elevation maxima follows a hump-shaped curve with a peak between $2000 \mathrm{~m}$ and $2200 \mathrm{~m}$ (Fig. 4). In contrast, the distribution of the species elevation minima shows a plateau between lowland and $1600 \mathrm{~m}$ and decreases rapidly between 1800 and $2400 \mathrm{~m}$ (Fig. 4). The important decrease of the minimum range values around $2000 \mathrm{~m}$ indicates that many species have their lower range limit around this elevation. As a result, many high and low elevation species have their lower and higher elevation limit near 2000 m respectively.

\section{Community phylogenetic turnover of beta-diversity}

We found a weak phylogenetic signal of niche conservatism (i.e. species-specific median of elevation distribution) across all plant species from the phylogeny (Blomberg's K: $\mathrm{K}=0.095, \mathrm{n}=231, \mathrm{Z}$-score $=-2.411, \mathrm{p}$-value $=0.002$ ), in Poales (Blomberg's $\mathrm{K}: \mathrm{K}=0.174, \mathrm{n}$ $=48$, Z-score $=-1.649, \mathrm{p}$-value $=0.022)$, Super-Rosids $($ Blomberg's K: K $=0.251, \mathrm{n}=50, \mathrm{Z}$ score $=-1.589, \mathrm{p}$-value $=0.003)$ and Super-Asterids (Blomberg's K: K =0.101, $\mathrm{n}=122, \mathrm{Z}$ score $=-1.194, p$-value $=0.1$. Only Super-Asterids showed a non-significant difference of Blomberg's K compared to a null distribution across the phylogeny, suggesting that the plant niche of Super-Asterids does not follow patterns of phylogenetic inertia.

The turnover rate in phylogenetic beta-diversity was more even along elevation across all plant species from the phylogeny (All plant species: linear $\mathrm{s}=2.6^{*} 10^{-2}$, quadratic $\mathrm{s}=$ $7.2^{*} 10^{-6}$ ) than the turnover rates in phylogenetic beta-diversity of Poales, Super-Rosids and Super-Asterids which were more uneven along elevation (Poales: linear $\mathrm{s}=0.188$, quadratic $\mathrm{s}=-5.5^{*} 10^{-5}$, Super-Rosids: linear $\mathrm{s}=0.138$, quadratic $\mathrm{s}=-3.3 * 10^{-5}$, Super-Asterids: linear $\mathrm{s}=$ $4.5^{*} 10^{-2}$, quadratic $s=1.5^{*} 10^{-5}$; Fig. $3 b$ ). Including quadratic terms improved the models of phylogenetic beta-diversity for all clades (AIC difference; All plant species $=-179.3$, Poales $=$ -1646.4, Super-Rosids = -257.6, Super-Asterids = -233.6), supporting the existence of a nonlinear relationship. The turnover rate in phylogenetic beta-diversity showed a strong humpshaped pattern in Poales (peak between 1700-1900m) and Super-Rosids (peak between 19002300m), while turnover rate in Super-Asterids was more even along elevation (Fig. 3b). The explained variance in the relationship between phylogenetic beta-diversity and elevation was higher in Poales $\left(R^{2}=0.236\right)$ and Super-Rosids $\left(R^{2}=0.164\right)$ than Super-Asterids $\left(R^{2}=0.056\right)$ or across all plant species from the phylogeny $\left(R^{2}=0.035\right)$. 
Plant clades show different patterns of distribution and dominance along elevation (Fig. 5, S4, S5, S6). Plant communities between 800 and $2800 \mathrm{~m}$ show a global decrease in the species proportion of Poales (from $28.6 \%$ at $1300 \mathrm{~m}$ to $11.6 \%$ at $2700 \mathrm{~m}$; Fig. 5) along elevation, with an increase in Super-Rosids (from $21 \%$ at 1500 m to $65.7 \%$ at 2900 m; Fig. 5) and a contrasting pattern for Super-Asterids (minimum $=14.8 \%$ at $2900 \mathrm{~m}$, maximum $=47.3 \%$ at 2100 m; Fig. 5). However, Poales species dominate plant communities in term of relative cover (i.e. bare soil and rock excluded; range: 42.8 - 58.7 \%; Fig. S5) compared to SuperRosids (range: 14.5 - 25 \%; Fig. S5) and Super-Asterids (range: 19.9 - 32.5 \%; Fig. S5), except in the highest bands. In Poales, Poaceae species dominate plant communities of low elevation and show a constant decrease of their relative cover from $900 \mathrm{~m}(57.3 \%)$ to $2700 \mathrm{~m}$ (31.3 \%; Fig. S5), while Cyperaceae species show a constant increase of their relative cover from $900 \mathrm{~m}(1.4 \%)$ to $2700 \mathrm{~m}$ (16.6\%; Fig. S5). In Super-Rosids and Super-Asterids, Fabaceae species have a higher relative cover at low elevations (10.4\% at 900 m; Fig. S5), Asteraceae and Apiaceae species at mid-elevations $(11.8 \%$ at $1900 \mathrm{~m}$ and $5.9 \%$ at $1500 \mathrm{~m}$, respectively; Fig. S5) and Saxifragaceae species dominate in relative cover plant communities of very high elevations (17.8 \% at $2700 \mathrm{~m}, 91.4 \%$ at $2900 \mathrm{~m}$; Fig. S5). Yet, the net breakpoint in the dominance of Saxifragaceae species above $2800 \mathrm{~m}$ is partly due to the smaller plot sampling and the small number of species occurring at this elevation, with a more regular transition when the real cover (i.e. bare soil and rock included) is considered (Fig. S6).

Overall, we found that the results were not sensitive to the resolution of elevation section considered, whether it is 10, 20 or 50 meters (Fig. S7, S8).

\section{Discussion}

Measures of species turnover are essential tools to investigate assemblage shifts along environmental gradients (Williams 1996), and particularly along elevation gradients which are commonly used as proxies of shifts in abiotic (see Körner 2007) and biotic conditions (Reynolds and Crossley 1997; Michalet et al. 2006; Körner 2007; Pellissier et al. 2014b; Michalet et al. 2015). Using this analytical tool, we showed that turnover rate along elevation in grassland communities is not constant but peaks around $1800-2200 \mathrm{~m}$, corresponding approximately to the regional treeline (1900 m, Gehrig-Fasel et al. 2007). The juxtaposition of highly dissimilar assemblages, large difference between gamma- and mean alpha-diversity (maximum between 1400-2100 m), and the high diversity of vegetation types (Fig. S3) 
indicate a singular ecological transition in this narrow elevation band (Fig. 2, 3, S3). This supports the hypothesis that across regional species pool in the Western Swiss Alps, many plant species share the same upper or lower elevation range limit (Fig. 4) and display "range boundary clumping" (Leibold and Mikkelson 2002). Human disturbances and current land management have probably favoured the mosaic of habitats occurring at mid-elevation. However, from the habitat data available, we found no evidence that the larger open areas or the higher diversity of vegetation types observed at mid elevation explain the observed taxonomic and phylogenetic turnover near the treeline. Together, our results document the singularity of grassland taxonomic and phylogenetic turnover at the border between the subalpine and alpine belts. Our study suggests that, like trees, this ecotone (Theurillat et al. 2003) constitutes a strong barrier for some herbaceous plant clades, even after centuries of land use (Tinner and Theurillat 2003). Despite grazing having shaped a continuum of open vegetation types across the subalpine and alpine belts, which should have since long allowed species exchanges along the elevation gradient (Vittoz et al. 2009), our results indicate the persistence of this ecotone.

The transition from the subalpine to the alpine belts, where the turnover was the most acute, is associated with several changes in the abiotic environment, including more stressful temperatures and a shorter growing season (Körner 2007). Enduring stressful abiotic conditions in the alpine belt requires particular and often convergent adaptations (Pellissier et al. 2010), including a lower stature (Körner 2003), a decreasing specific leaf area (Salinas et al. 2011) associated to slower growth rates (Whittaker 1956). Plant distribution may also be limited by other abiotic factors in the alpine belt, including strong wind, ground instability, the type of underground rock (i.e. calcareous or siliceous), or frost during the growing season, which can result in functionally distinct plant communities at high compared to low elevations (Diaz and Cabido 1997). While clumped minima and maxima elevation range values observed around the treeline is expected to be partially controlled by abiotic factors (Diaz and Cabido 1997), changes in biotic interactions might also modulate plant range limit at the subalpinealpine ecotone. In symmetry to the stressful abiotic conditions limiting lowland species in the alpine belt, higher competition among plant species (Choler et al. 2001; Alexander et al. 2015) and higher insect herbivore pressure on poorly defended alpine species in the subalpine belt likely limits the growth of small alpine plant species (Galen 1990; Bruelheide and Scheidel 1999; Pellissier et al. 2012; Pellissier et al. 2014b). However, high grazing pressure by cows or sheep in subalpine pastures can also reduce plant competition and favour the establishment of alpine plants at lower elevation (Vittoz et al. 2009). Moreover, higher 
species richness could also be favoured at intermediate position along environmental severity gradients as a result of decreasing inter-specific competition and increasing stress-tolerance with elevation (Michalet et al. 2006; Holmgren and Scheffer 2010; Verwijmeren et al. 2013; Michalet et al. 2015) favouring the mixture of low competitive species and high elevation stress-tolerant species (Michalet et al. 2015). Our results contrast with a study in Norway where no major discontinuity in species richness, composition or turnover was observed at the forest-limit ecotone (Odland and Birks 1999).

Taxonomic turnover component of beta-diversity was associated to uneven phylogenetic turnover rate along elevation. Poales and Super-Rosids showed a significant but weak phylogenetic conservatism of species range and an acceleration of phylogenetic turnover with a peak reached around $1900 \mathrm{~m}$ for both clades (Fig. 3b). This corroborates the finding of Ndiribe et al. (2013) showing singular phylogenetic diversity patterns in Liliopsida (i.e. incl. Poales) along elevation. Several Poales and Super-Rosids lineages showed a preference either for the montane-subalpine or for the alpine environment, shaping the higher lineage turnover at the subalpine-alpine ecotone. For instance, the species in the genus Carex (Cyperaceae) show a preference for mid-elevation environments (i.e. 1300 - 2500 m; Fig. 5, Fig. S5), the species in the genus Saxifraga (Saxifragaceae) show a preference to colder environment above the treeline (i.e. $>2100$ m; Fig. 5, S5) and the species in the Fabaceae family show a preference for lower elevation environments (i.e. <2300 m; Fig. 5, S5). Many Carex species are tolerant to low temperatures (Körner 2003) and can be dominant and diversified in communities above the treeline (Grabherr 1989; Körner 2003). Conversely, Poaceae generally dominate grasslands below treeline (Fig. S5). In different regions, phylogenetic patterns in Liliopsida distinct from coexisting Magnolopsida have been reported along environmental gradients (Silvertown et al. 2001; Cahill et al. 2008). For instance, Cahill et al. (2008) observed that the intensity of competition showed a stronger phylogenetic signal in Liliopsida than Magnolopsida, as a consequence of higher niche conservatism in Liliopsida. Moreover, phylogenetic turnover is not always associated to functional turnover, due to possible convergence of traits between phylogenetically distinct species groups (Godoy et al. 2014). The lower phylogenetic conservatism of Super-Asterids range suggests that most lineages contain species that are distributed both above and below the treeline, explaining the constant lineage turnover rate along elevation (Fig. 3b; Chalmandrier et al. 2015). This constant phylogenetic turnover contrasts with the observed peak of taxonomic turnover at mid-elevation for Super-Asterids (Fig. 3), indicating that taxonomic turnover is not always associated to phylogenetic turnover. Similarly, Ndiribe et al. (2013a) found prevailing 
patterns of phylogenetic overdispersion in three families of the Super-Asterids clade (i.e. Apiaceae, Lamiaceae and Asteraceae families), indicating that closely related species diversified to occupy communities in contrasting environmental conditions, or that close relatives co-occur less often than expected. The low niche conservatism observed in SuperAsterids could be due to strong rates of evolution occurring in this clade favouring niche differentiation (Cooper et al. 2010) or the lack of high/low elevation specialized clades (i.e. lack of species in the Fabaceae and Saxifragaceae families, respectively), which may in part be attributed to their life-history traits (Ndiribe et al. 2013a). For instance, species of the Lamiaceae family have evolved phenolic compounds providing herbivore resistance and favouring their persistence in communities in contrasted environmental conditions (Grøndahl and Ehlers 2008).

Compared to gamma-diversity, the peak in alpha-diversity occurs at a lower elevation around $1100-1500 \mathrm{~m}$, indicating that plant community richness is not necessary strictly associated to a higher species richness in a local pool. Alpha-diversity seems to reflect the disturbances occurring on plant communities at both ends of the elevation gradient, with more intensive land use (pastures, fertilization) at low elevation increasing plant exclusion by competition (Eriksson et al. 1995; Foster and Gross 1998) and limiting the diversity of vegetation types (Fig. S3) and severe environmental conditions at high elevation allowing the growth of few stress tolerant species. Before the intensification of agriculture, beginning around 60 years ago, dry and oligotrophic grasslands were more frequent below $1100 \mathrm{~m}$ (Lachat et al. 2010) and a similar analysis would have probably not resulted in so steep decline of alpha-diversity at low elevations. These grasslands are very species rich but are now very rare in the landscape at low elevations. A higher intensity of land use may also explain the lower gamma-diversity occurring at low elevation, which tends to homogenise the composition of plant communities. The land use at low elevation and the high elevation stress could explain the higher nestedness pattern below $1200 \mathrm{~m}$ and above $2200 \mathrm{~m}$. In alpine habitat, communities with lower species richness are more frequently a subset of richer alpine communities. Since alpine habitats are supposed to be more stochastic due to stronger temporal variations in environmental conditions such as solifluction or landslides, some communities may suffer random loss of species shaping nestedness in the alpine belt (Körner 2003). Nestedness below $1200 \mathrm{~m}$ is probably the result of the intensive land use (i.e. pasturing, grazing, mowing, and fertilization), which limits plant composition to the more competitive species, subset of richer lowland communities. 
Climate change is currently increasing temperature in the Alps with rapid detectable

452 changes in alpine plant communities (Pauli et al. 2012). Based on the present study, we can

453 expect that the same temperature rise along the elevation gradient may not trigger the same

454 amount of turnover rate in communities. In the transition between the subalpine and alpine

455 belts, distinct flora are juxtaposed and only a strong ecological barrier appears to keep them

456 apart. Climate change may lift the existing barrier across the subalpine-alpine ecotone,

457 allowing for the upward movement and invasion of more competitive subalpine plants in the

458 alpine grasslands, shaping novel assemblages and potentially causing local extinction of

459 species in those communities (Alexander et al. 2015). Monitoring scheme investigating plant

460 community changes along wide elevation gradients are required to evaluate the speed of

461 changes (Vittoz et al. 2010). While the absence of change in the turnover rate of phylogenetic

462 beta-diversity along elevation were documented (Bryant et al. 2008; Chalmandrier et al.

463 2015), our study reports a strong species turnover between the subalpine and alpine vegetation

464 belts and suggests that climate change might, in turn, have an uneven impact on species'

465 range shifts across the elevation gradient. 


\section{References}

Alexander JM, Diez JM, Levine JM (2015) Novel competitors shape species' responses to climate change. Nature 525:515-518. doi: 10.1038/nature14952

Bach K, Kessler M, Gradstein SR (2007) A simulation approach to determine statistical significance of species turnover peaks in a species-rich tropical cloud forest. Divers Distrib 13:863-870. doi: 10.1111/j.1472-4642.2007.00357.x

Baselga A (2012) The relationship between species replacement, dissimilarity derived from nestedness, and nestedness. Glob Ecol Biogeogr 21:1223-1232.

Baselga A (2010) Partitioning the turnover and nestedness components of beta diversity. Glob Ecol Biogeogr 19:134-143. doi: 10.1111/j.1466-8238.2009.00490.x

Baselga A, Leprieur F (2015) Comparing methods to separate components of beta diversity. Methods Ecol Evol 6:1069-1079.

Baselga A, Orme CDL (2012) betapart: an R package for the study of beta diversity. Methods Ecol Evol 3:808-812. doi: 10.1111/j.2041-210X.2012.00224.X

Blomberg SP, Garland T, Ives AR (2003) Testing for phylogenetic signal in comparative data: behavioral traits are more labile. Evolution (N Y) 57:717-745. doi: 10.1111/j.00143820.2003.tb00285.x

Bouët M (1985) Climat et météorologie de la Suisse romande. Payot, Lausanne

Bruelheide H, Scheidel U (1999) Slug herbivory as a limiting factor for the geographical range of Arnica montana. J Ecol 87:839-848. doi: 10.1046/j.1365-2745.1999.00403.x

Bryant J a, Lamanna C, Morlon H, et al (2008) Microbes on mountainsides: contrasting elevational patterns of bacterial and plant diversity. Proc Natl Acad Sci U S A 105:11505-11511. doi: 10.1073/pnas.0801920105

Cahill JF, Kembel SW, Lamb EG, Keddy PA (2008) Does phylogenetic relatedness influence the strength of competition among vascular plants? Perspect Plant Ecol Evol Syst 10:4150. doi: 10.1016/j.ppees.2007.10.001

Chalmandrier L, Münkemüller T, Lavergne S, Thuiller W (2015) Effects of species' similarity and dominance on the functional and phylogenetic structure of a plant meta-community. Ecology 96:153-153. doi: 10.1890/13-2153.1

Choler P, Michalet R, Callaway RM (2001) Facilitation and competition on gradients in alpine plant communities. Ecology 82:3295-3308. doi: 10.1890/00129658(2001)082[3295:FACOGI]2.0.CO;2

Clements FE (1916) Plant succession: an analysis of the development of vegetation. Carnegie Institution, Washington

Cooper N, Jetz W, Freckleton RP (2010) Phylogenetic comparative approaches for studying niche conservatism. J Evol Biol 23:2529-2539.

Culmsee H, Leuschner C (2013) Consistent patterns of elevational change in tree taxonomic and phylogenetic diversity across Malesian mountain forests. J Biogeogr 40:1997-2010. doi: $10.1111 /$ jbi.12138

de Bello F, Lavorel S, Lavergne S, et al (2013) Hierarchical effects of environmental filters on the functional structure of plant communities: a case study in the French Alps. 
Ecography (Cop) 36:393-402. doi: 10.1111/j.1600-0587.2012.07438.x

Delarze R, Gonseth Y (2008) Guide des milieux naturels de Suisse. Ecologie - Menaces Espèces caractéristiques. Rossolis, Bussigny

Diaz S, Cabido M (1997) Plant functional types and ecosystem function in relation to global change. J Veg Sci 8:463-474. doi: 10.2307/3237198

Dubuis A, Pottier J, Rion V, et al (2011) Predicting spatial patterns of plant species richness: a comparison of direct macroecological and species stacking modelling approaches. Divers Distrib 17:1122-1131.

Eriksson Å, Eriksson O, Berglund H (1995) Species abundance patterns of plants in Swedish semi-natural pastures. Ecography (Cop) 18:310-317.

Fischer M, Rudmann-Maurer K, Weyand A, Stöcklin. J (2008) Agricultural land use and biodiversity in the Alps - How cultural tradition and socioeconomically motivated changes are shaping grassland biodiversity in the Swiss Alps. Mt Res Dev 28:148-155.

Foster BL, Gross KL (1998) Species richness in a successional grassland: effects of nitrogen enrichment and plant litter. Ecology 79:2593-2602.

Galen C (1990) Limits to the distributions of alpine tundra plants: herbivores and the alpine skypilot, Polemonium viscosum. Oikos 59:355-358.

Garibaldi LA, Kitzberger T, Chaneton EJ (2011) Environmental and genetic control of insect abundance and herbivory along a forest elevational gradient. Oecologia 167:117-129. doi: 10.1007/s00442-011-1978-0

Gaston KJ, Blackburn TIMM, Greenwoodx JD, et al (2000) Abundance-occupancy relationships. J Appl Ecol 37:39-59. doi: 10.1046/j.1365-2664.2000.00485.x

Gehrig-Fasel J, Guisan A, Zimmermann NE (2007) Tree line shifts in the Swiss Alps: climate change or land abandonment? J Veg Sci 18:571-582. doi: 10.1111/j.16541103.2007.tb02571.x

Gentry AH (1988) Changes in plant community diversity and floristic composition on environmental and geographical gradients. Ann Missouri Bot Gard 75:1-34.

Gleason HA (1926) The individualistic concept of the plant association. Bull Torrey Bot Club $53: 7-26$.

Godoy O, Kraft NJ, Levine JM (2014) Phylogenetic relatedness and the determinants of competitive outcomes. Ecol Lett 17:836-844.

Grabherr G (1989) On community structure in high alpine grasslands. Vegetatio 83:223-227. doi: 10.1007/BF00031694

Graham CH, Fine PV a (2008) Phylogenetic beta diversity: Linking ecological and evolutionary processes across space in time. Ecol Lett 11:1265-1277. doi: 10.1111/j.1461-0248.2008.01256.x

Graham JH, Krzysik AJ, Kovacic D a., et al (2009) Species richness, equitability, and abundance of ants in disturbed landscapes. Ecol Indic 9:866-877. doi: 10.1016/j.ecolind.2008.10.003

Grøndahl E, Ehlers BK (2008) Local adaptation to biotic factors: reciprocal transplants of four species associated with aromatic Thymus pulegioides and T. serpyllum. J Ecol 96:981-992. 
Hirzel A, Guisan A (2002) Which is the optimal sampling strategy for habitat suitability modelling. Ecol Modell 157:331-341.

Holmgren M, Scheffer M (2010) Strong facilitation in mild environments: the stress gradient hypothesis revisited. J Ecol 98:1269-1275. doi: 10.1111/j.1365-2745.2010.01709.x

Hutchinson EG (1957) Concluding remarks. Cold Spring Harb Symp Quant Biol 22:415-427.

Jankowski JE, Ciecka AL, Meyer NY, Rabenold KN (2009) Beta diversity along environmental gradients: Implications of habitat specialization in tropical montane landscapes. J Anim Ecol 78:315-327. doi: 10.1111/j.1365-2656.2008.01487.x

Jankowski JE, Merkord CL, Rios WF, et al (2013) The relationship of tropical bird communities to tree species composition and vegetation structure along an Andean elevational gradient. J Biogeogr 40:950-962. doi: 10.1111/jbi.12041

Kembel SW, Cowan PD, Helmus MR, et al (2010) Picante: R tools for integrating phylogenies and ecology. Bioinformatics 26:1463-1464. doi: 10.1093/bioinformatics/btq166

Kembel SW, Hubbell SP (2006) The phylogenetic structure of a neotropical forest tree community. Ecology 87:S86-S99.

Körner C (2007) The use of "altitude" in ecological research. Trends Ecol Evol 22:569-574. doi: 10.1016/j.tree.2007.09.006

Körner C (2003) Alpine plant life: functional plant ecology of high mountain ecosystems; with 47 tables. Springer Science \& Business Media

Körner C (2000) Why are there global gradients in species richness? Mountains might hold the answer. Trends Ecol Evol 15:513-514. doi: 10.1016/S0169-5347(00)02004-8

Lachat T, Pauli D, Gonseth Y, et al (2010) Wandel der Biodiversität in der Schweiz seit 1900. Ist die Talsohle erreicht?, Haupt Verl. Berne.

Leibold MA, Mikkelson GM (2002) Coherence, species turnover, and boundary clumping: elements of meta-community structure. Oikos 97:237-250. doi: 10.1034/j.16000706.2002.970210.x

Longino JT, Colwell RK (2011) Density compensation, species composition, and richness of ants on a neotropical elevational gradient. Ecosphere 2:art29. doi: 10.1890/ES10-00200.1

Mena JL, Vázquez-Domínguez E (2005) Species turnover on elevational gradients in small rodents. Glob Ecol Biogeogr 14:539-547. doi: 10.1111/j.1466-822X.2005.00189.x

Michalet R, Brooker RW, Cavieres LA, et al (2006) Do biotic interactions shape both sides of the humped-back model of species richness in plant communities? Ecol Lett 9:767-773. doi: 10.1111/j.1461-0248.2006.00935.x

Michalet R, Maalouf JP, Choler P, et al (2015) Competition, facilitation and environmental severity shape the relationship between local and regional species richness in plant communities. Ecography (Cop) 38:335-345. doi: 10.1111/ecog.01106

Ndiribe C, Pellissier L, Antonelli S, et al (2013a) Phylogenetic plant community structure along elevation is lineage specific. Ecol Evol 3:4925-4939. doi: 10.1002/ece3.868

Ndiribe C, Pellissier L, Dubuis a., et al (2013b) Plant functional and phylogenetic turnover correlate with climate and land use in the Western Swiss Alps. J Plant Ecol 1-12. doi: 10.1093/jpe/rtt064 
Niedrist G, Tasser E, Luth C, et al (2009) Plant diversity declines with recent land use changes in European Alps. Plant Ecol 202:195-210.

Odland A, Birks HJB (1999) The altitudinal gradient of vascular plant richness in Aurland, western Norway. Ecography (Cop) 22:548-566.

Pauli H, Gottfried M, Dullinger S, et al (2012) Recent plant diversity changes on Europe's mountain summits. Science (80- ) 336:353 - 355. doi: 10.1126/science. 1219033

Pellissier L, Alvarez N, Espindola A, et al (2013a) Phylogenetic alpha and beta diversities of butterfly communities correlate with climate in the western Swiss Alps. Ecography (Cop) 36:541-550. doi: 10.1111/j.1600-0587.2012.07716.x

Pellissier L, Fiedler K, Ndribe C, et al (2012) Shifts in species richness, herbivore specialization, and plant resistance along elevation gradients. Ecol Evol 2:1818-1825. doi: 10.1002/ece3.296

Pellissier L, Fournier B, Guisan A, Vittoz P (2010) Plant traits co-vary with altitude in grasslands and forests in the European Alps. Plant Ecol 211:351-365. doi: $10.1007 / \mathrm{s} 11258-010-9794-\mathrm{x}$

Pellissier L, Ndiribe C, Dubuis A, et al (2013b) Turnover of plant lineages shapes herbivore phylogenetic beta diversity along ecological gradients. Ecol Lett 16:600-608. doi: 10.1111/ele.12083

Pellissier L, Niculita-Hirzel H, Dubuis A, et al (2014a) Soil fungal communities of grasslands are environmentally structured at a regional scale in the Alps. Mol Ecol 23:4274-4290. doi: $10.1111 /$ mec. 12854

Pellissier L, Roger A, Bilat J, Rasmann S (2014b) High elevation Plantago lanceolata plants are less resistant to herbivory than their low elevation conspecifics: is it just temperature? Ecography (Cop) 37:950-959. doi: 10.1111/ecog.00833

Pottier J, Dubuis A, Pellissier L, et al (2013) The accuracy of plant assemblage prediction from species distribution models varies along environmental gradients. Glob Ecol Biogeogr 22:52-63. doi: 10.1111/j.1466-8238.2012.00790.x

Qian H, Ricklefs RE, White PS (2005) Beta diversity of angiosperms in temperate floras of eastern Asia and eastern North America. Ecol Lett 8:15-22. doi: 10.1111/j.14610248.2004.00682.x

Reynolds BC, Crossley DAJ (1997) Spatial variation in herbivory by forest canopy arthropods along an elevation gradient. Environ Entomol 26:1232-1239.

Salinas N, Malhi Y, Meir P, et al (2011) The sensitivity of tropical leaf litter decomposition to temperature: Results from a large-scale leaf translocation experiment along an elevation gradient in Peruvian forests. New Phytol 189:967-977. doi: 10.1111/j.14698137.2010.03521.x

Sanders NJ (2002) Elevational gradients in ant species richness: area, geometry, and Rapoport's rule. Ecography (Cop) 25:25-32. doi: 10.1034/j.1600-0587.2002.250104.x

Silvertown J, Dodd M, Gowing D (2001) Phylogeny and the niche structure of meadow plant communities. J Ecol 89:428-435. doi: 10.1046/j.1365-2745.2001.00553.x

Soberón J (2007) Grinnellian and Eltonian niches and geographic distributions of species. Ecol Lett 10:1115-1123.

Theurillat J, Schlüssel A, Geissler P, et al (2003) Vascular plant and bryophyte diversity along 
elevation gradients in the alps. In: Ecological Studies. Springer Berlin, Heidelberg, pp $185-193$

Tinner W, Theurillat J-P (2003) Uppermost limit, extent, and fluctuations of the timberline and treeline ecocline in the Swiss central Alps during the past 11,500 years. Arctic, Antarct Alp Res 35:158-169. doi: 10.1657/15230430(2003)035\{[\}0158:ULEAFO]2.0.CO;2

Tuomisto H (2010) A diversity of beta diversities: Straightening up a concept gone awry. Part 1. Defining beta diversity as a function of alpha and gamma diversity. Ecography (Cop) 33:2-22. doi: 10.1111/j.1600-0587.2009.05880.x

Ulrich W, Gotelli NJ (2007) Null model analysis of species nestedness patterns. Ecology 88:1824-1831. doi: 10.1890/06-1208.1

Verwijmeren M, Rietkerk M, Wassen MJ, Smit C (2013) Interspecific facilitation and critical transitions in arid ecosystems. Oikos 122:341-347. doi: 10.1111/j.16000706.2012.00111.x

Vittoz P, Camenisch M, Mayor R, et al (2010) Subalpine-nival gradient of species richness for vascular plants, bryophytes and lichens in the Swiss Inner Alps. Bot Helv 120:139149. doi: 10.1007/s00035-010-0079-8

Vittoz P, Randin C, Dutoit A, et al (2009) Low impact of climate change on subalpine grasslands in the Swiss Northern Alps. Glob Chang Biol 15:209-220. doi: 10.1111/j.1365-2486.2008.01707.x

Whittaker RH (1956) Vegetation of the Great Smoky Mountains. Ecol Monogr 26:1-80.

Wiens JJ, Ackerly DD, Allen AP, et al (2010) Niche conservatism as an emerging principle in ecology and conservation biology. Ecol Lett 13:1310-1324. doi: 10.1111/j.14610248.2010.01515.x

Williams PH (1996) Mapping variations in the strength and breadth of biogeographic transition zones using species turnover. Proc R Soc London B Biol Sci 263:579-588.

Wright DH, Reeves JH (1992) On the meaning and measurement of nestedness of species assemblages. Oecologia 92:416-428. doi: 10.1007/BF00317469 
665 Additional supporting information in the online version of this article (see „Supplementary 666 Material") contains the following:

667 Appendix S1. Methodological details about OLS models and variable partition analyses

668 Fig. S1 Number of open areas and plots along the elevation gradient in the study area.

669 Fig. S2 Principal Components Analysis of sampled plot location in the environmental space.

670 Fig. S3 Number of vegetation types along the elevation gradient.

671 Fig. S4 Proportion of the main vascular plant clades in elevation bands of $200 \mathrm{~m}$.

672 Fig. S5 Mean relative cover of the main vascular plant clades in elevation bands of $200 \mathrm{~m}$.

673 Fig. S6 Mean cover of the main vascular plant clades in elevation bands of $200 \mathrm{~m}$.

674 Fig. S7 Diversity changes along the elevation gradient obtained by comparing plant 675 communities of the same elevation $( \pm 10 \mathrm{~m} \mathrm{\&} \pm 50 \mathrm{~m})$.

676 Fig. S8 Diversity changes and relationship between elevation and plant relatedness in plant 677 community turnover of the same elevation $( \pm 10 \mathrm{~m} \& \pm 50 \mathrm{~m})$ for 3 plant clades.

678 
680

681

682

Fig. 1 Location of the study area in the western Alps of Switzerland. The red dots represent vegetation sampling sites and green areas represent forests ecosystems. The light grey line shows the limits of study area. The dark grey line shows the $800 \mathrm{~m}$ isoline.

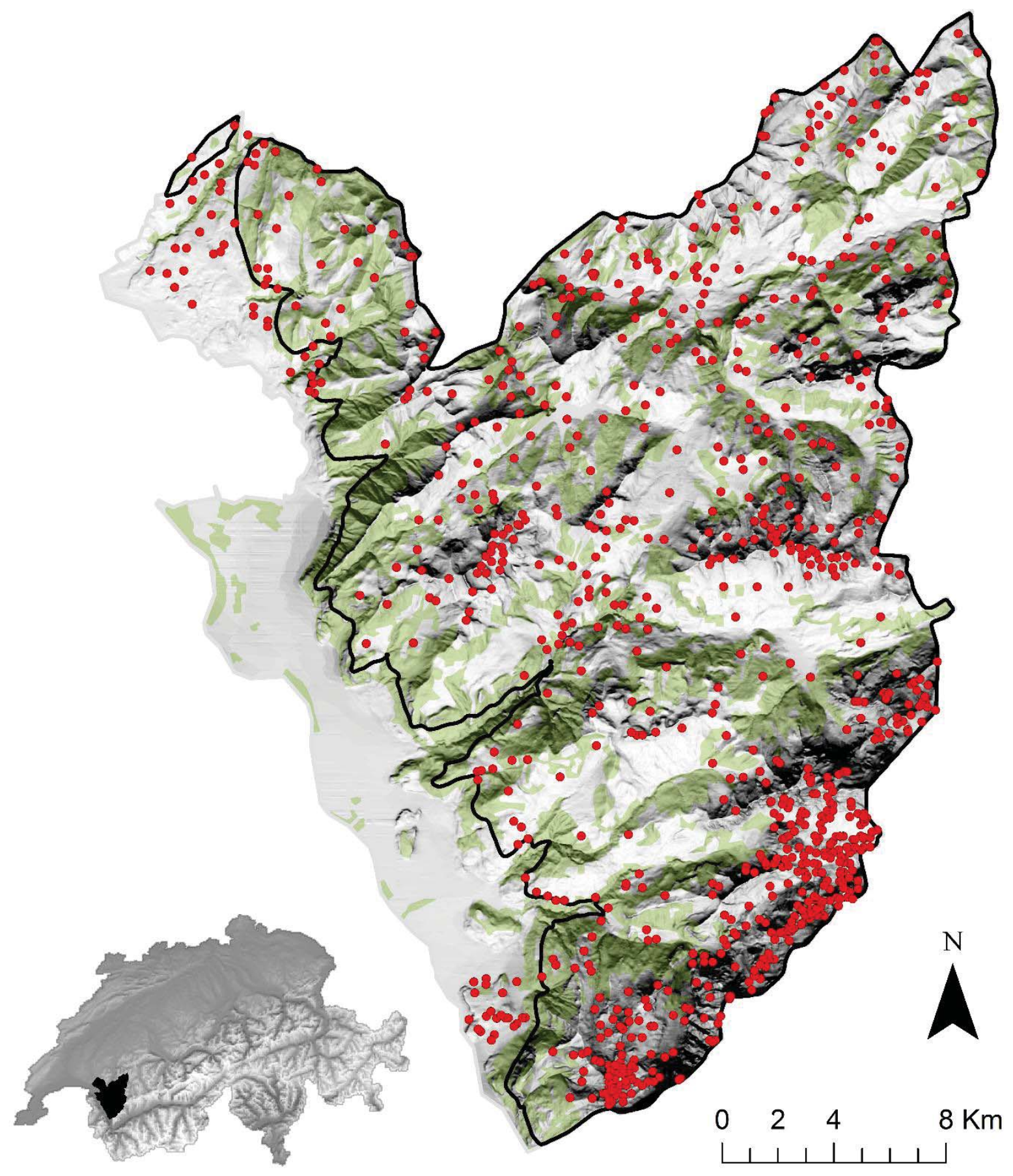


687

688

689

690

691

692

693

694

695

696

697

698

699

700

Fig. 2 Diversity changes along elevation gradients obtained by comparing plant communities within 20 m elevation bands as a measure of (a) mean community diversity (black points; mean alpha-diversity), total species richness (green points; gamma-diversity) and (b) proportion of species turnover (black points; turnover component of beta-diversity) and nestedness (green points; nestedness component of beta-diversity). Curves represent the quadratic relationships. Dashed lines represent the 5 and 95 percentiles.

(a)

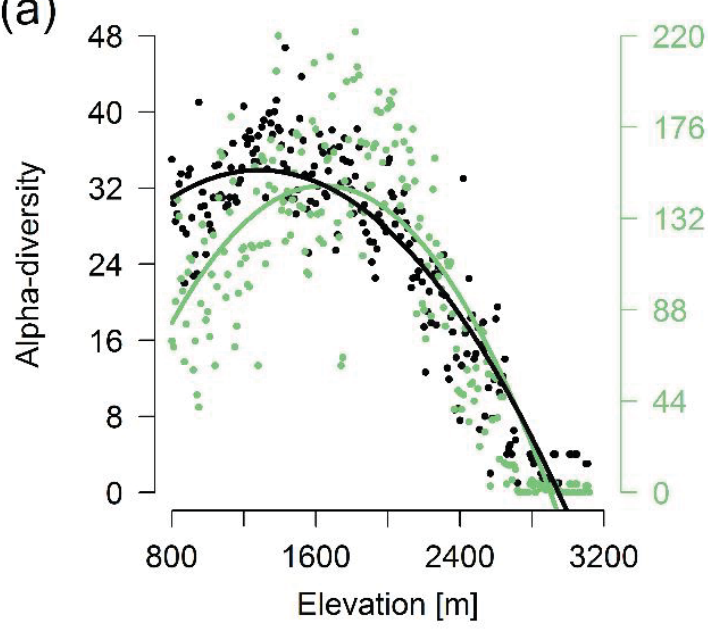

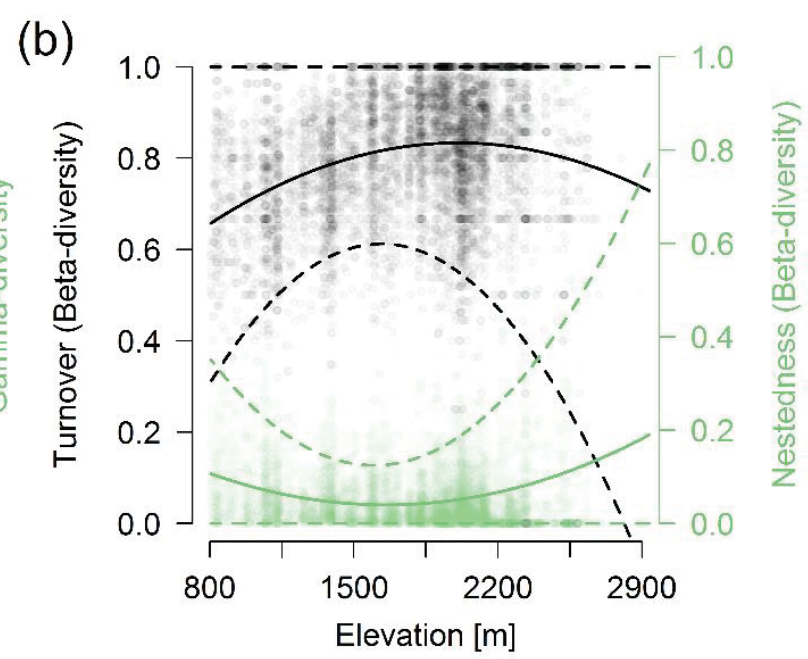

Fig. 3 Relationship between elevation and (a) proportion of plant species turnover (turnover component of beta-diversity) and (b) phylogenetic plant relatedness calculated as the mean pairwise distance (MPD) separating taxa in pairs of plant inventories of the same elevation (range $20 \mathrm{~m}$ ) for Super-Asterids (black points), Super-Rosids (blue points) and Poales (red points) clades. Curves represent the quadratic relationships.

(a)

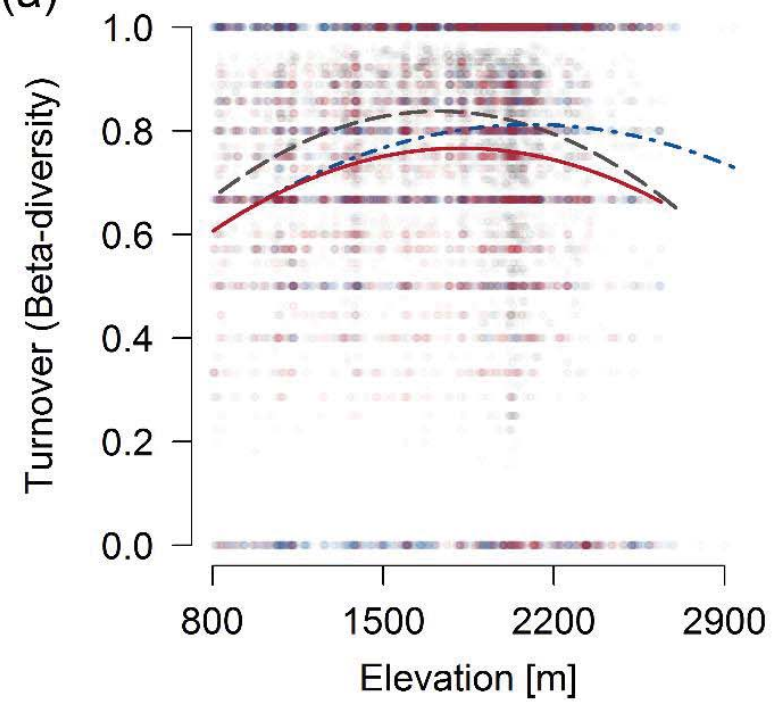

(b)

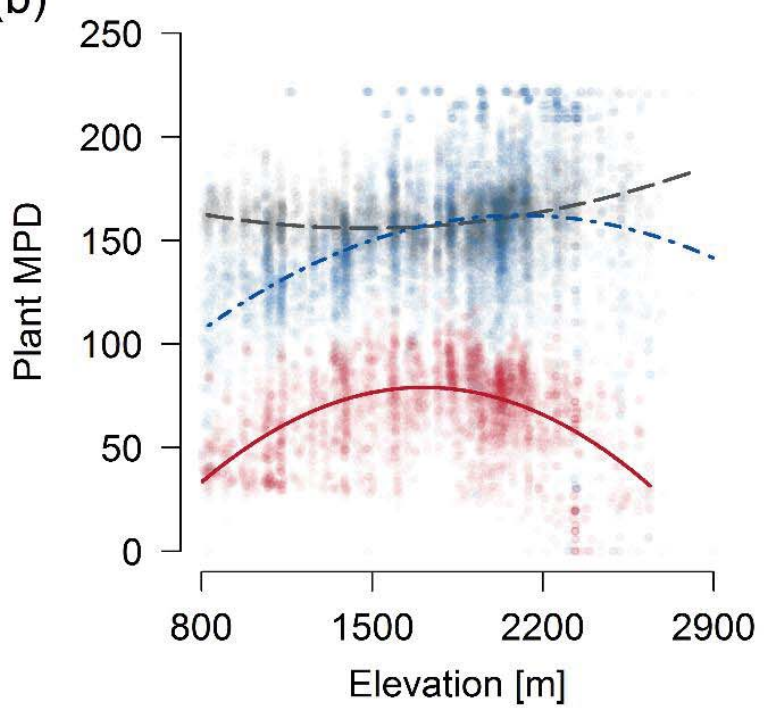


Fig. 4 Distribution of the minimum (black) and maximum (grey) elevation of the species ranges in elevation bands of $20 \mathrm{~m}$ for each $10 \mathrm{~m}$ along the elevation gradient in the study area. Curves were fitted with a GAM function.

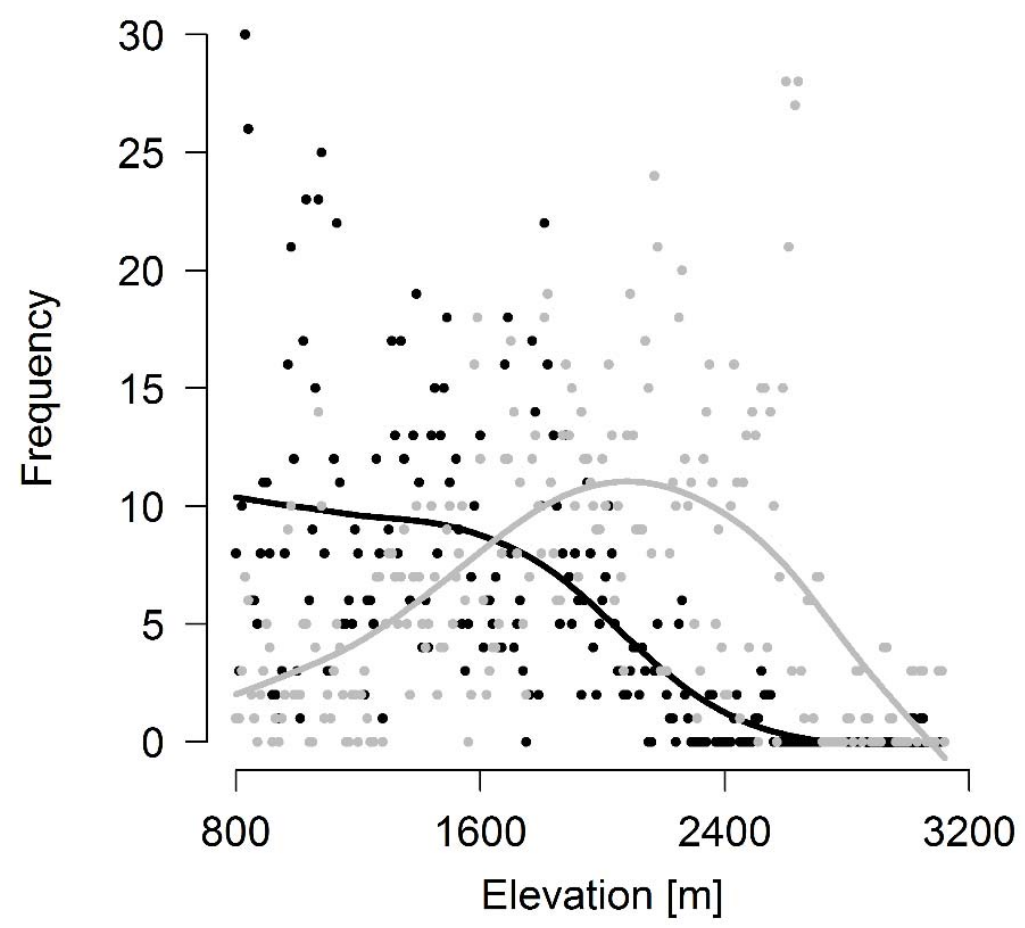

Fig. 5 Mean proportion of occurrences of the main vascular plant clades in plant communities in elevation bands of $200 \mathrm{~m}$. Each color represents the mean proportion of the plant clade in plant communities for the corresponding elevation band. The different shades of red-orange correspond to Poales, the blue shades to Super-Rosids and the grey-black shades to SuperAsterids.

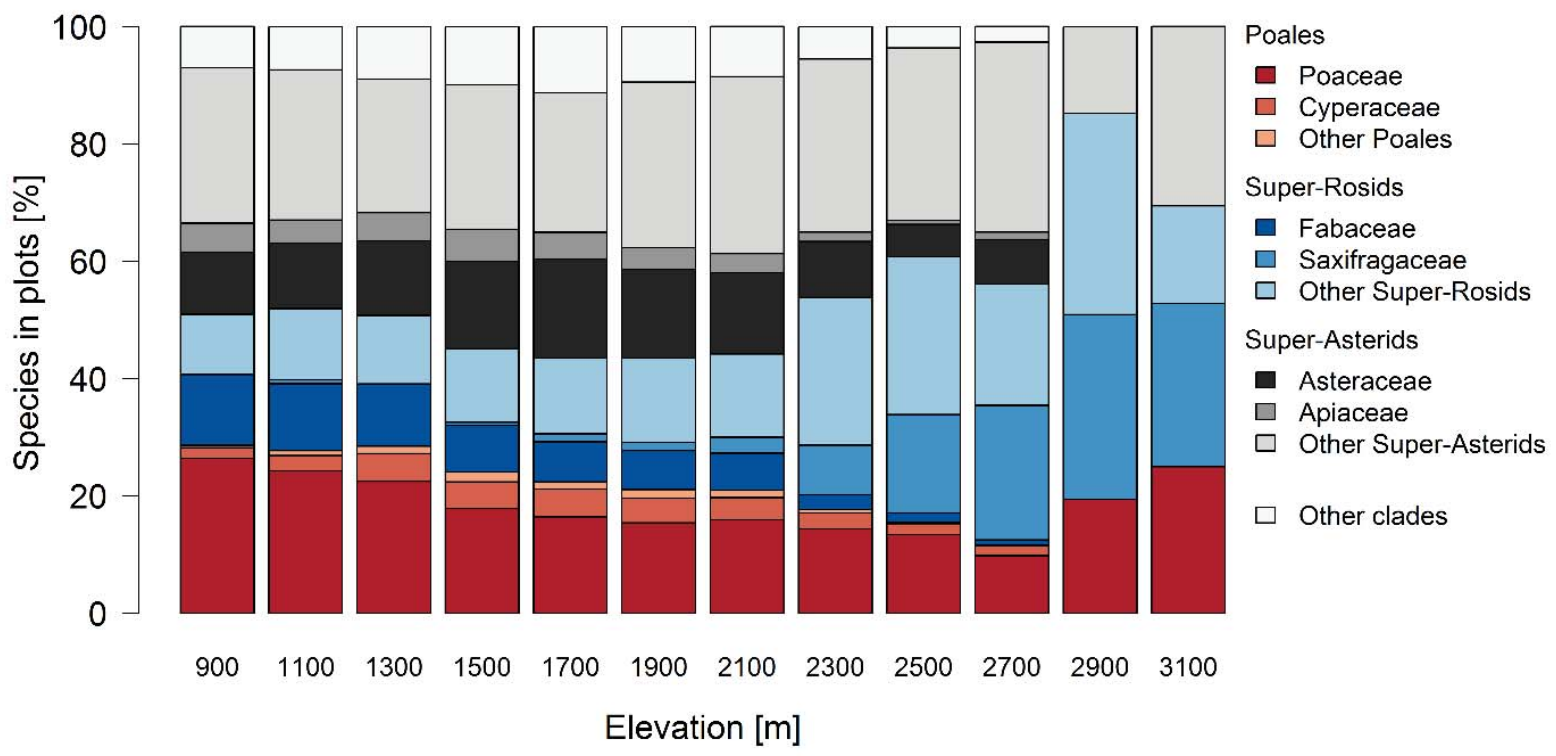


Research article for Alpine Botany

\section{Uneven rate of plant turnover along elevation in grasslands}

Patrice Descombes ${ }^{1,2 *}$, Pascal Vittoz ${ }^{3}$, Antoine Guisan ${ }^{3,4}$, Loïc Pellissier ${ }^{1,2}$

${ }^{1}$ Landscape Ecology, Institute of Terrestrial Ecosystems, ETH Zürich, CH-8092 Zürich,

Switzerland

${ }^{2}$ Swiss Federal Research Institute WSL, CH-8903 Birmensdorf, Switzerland

${ }^{3}$ University of Lausanne, Institute of Earth Surface Dynamics, Géopolis, CH-1015 Lausanne, Switzerland

${ }^{4}$ University of Lausanne, Department of Ecology and Evolution, Biophore, CH-1015

Lausanne, Switzerland

* Corresponding author: Patrice Descombes, patrice.descombes@wsl.ch

\section{Supplementary materials}




\section{Appendix S1. Methodological details about OLS models and variable partition analyses}

\section{OLS models}

We compared the turnover component of beta-diversity to elevation and habitat variables (frequency of open areas and diversity of vegetation types) by using an ordinary least squares regression (OLS) model and including all predictor variables and quadratic terms to account for non-linear relationships. The proportion of variation in the turnover component of betadiversity explained by the OLS models was quantified with the coefficient of determination $\left(R^{2}\right)$.

\section{Variable partition analyses}

In addition, we quantified the relative importance of elevation vs. habitat variables (i.e. frequency of open areas and diversity of vegetation types) for explaining beta-diversity variation by using a variance partitioning analyses (Borcard et al., 1992). This analysis decomposes the proportion of variation in beta-diversity explained by the full OLS model $\left(R^{2}\right)$ into two sources of variation by means of partial regressions (Legendre, 2012): (i) variation due to the independent effect of the elevation variable, (ii) variation due to the independent effect of habitat variables, and (iii) variation due to the combined effect of elevation and habitat variables. When partitioning the explained variance of beta-diversity $\left(R^{2}=0.21\right)$, among elevation and habitat variables in OLS full models, elevation displayed the strongest independent effect, with a higher independent proportion of explained variance $(11.7 \%)$ than habitat variables $(0.0 \%)$.

\section{References}

Borcard D, Legendre P, \& Drapeau P (1992) Partialling out the Spatial Component of Ecological Variation. Ecology 73:1045-1055.

Legendre L (2012) Numerical Ecology. Elsevier, Amsterdam. 


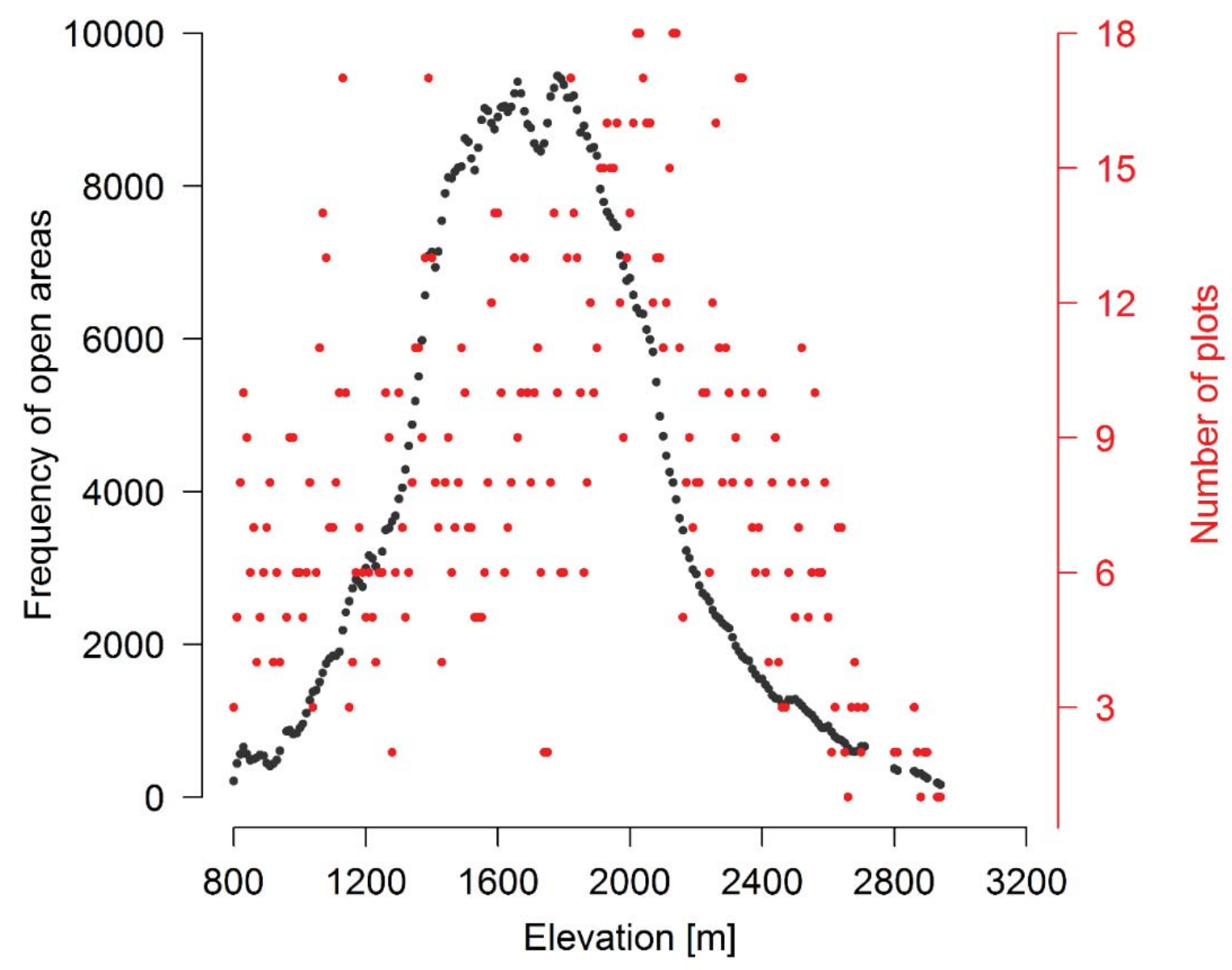

Fig. S1 Number of open areas (black points) and plots (red points) in elevation bands of $20 \mathrm{~m}$ for each $10 \mathrm{~m}$ along the elevation gradient in the study area. The unit of open areas is the number of pixels in elevation bands at a resolution of $25 \mathrm{~m}$. 


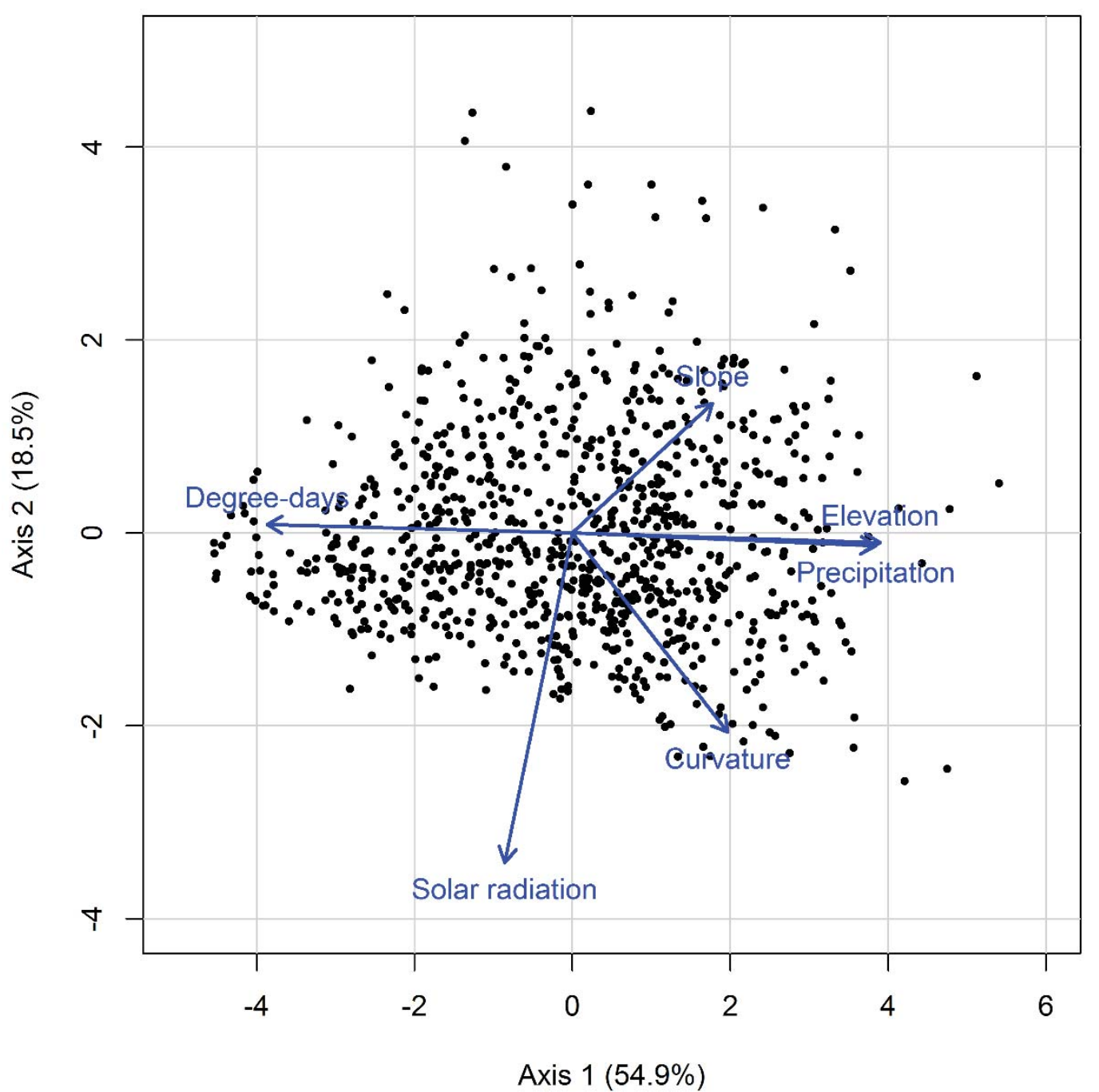

Fig. S2 Principal Components Analysis based on plot location (points) related to six environmental variables (blue arrows): elevation, annual sum of precipitation, annual sum of degree-days (better factor than mean temperature to explain plan distribution; Zimmermann and Kienast 1999), annual sum of solar radiation, curvature (related to shape of land, with negative values for concave areas, positive values for convex areas and 0 for flat areas or regular slopes) and slope. The two first axes of the initial PCA explained $73.4 \%$ of the total variance (axis 1, 54.9\%; axis 2, $18.5 \%$ ). The length of the vectors represents the magnitude of the correlation between the variables and the axes. 


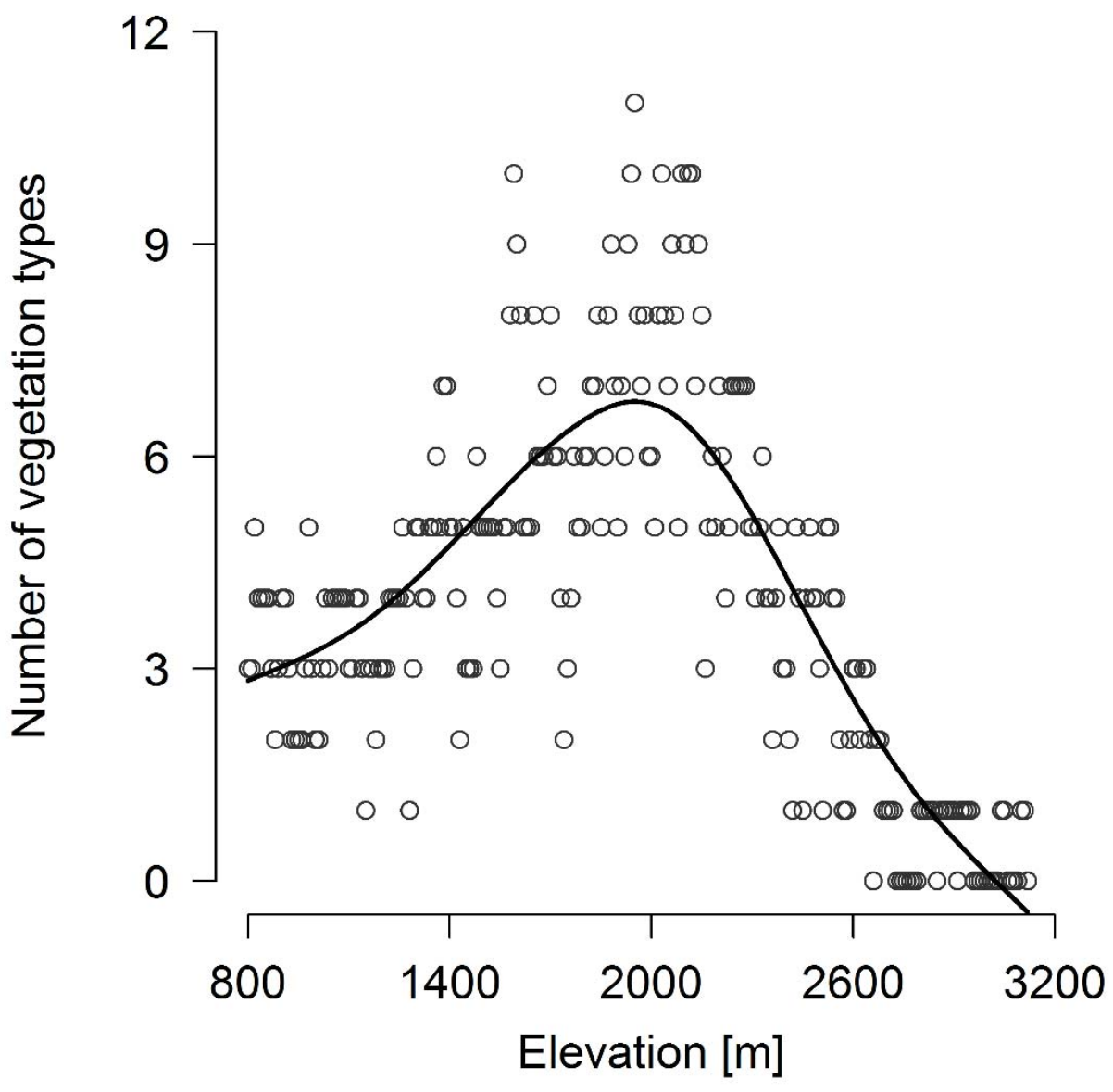

Fig. S3 Number of vegetation types among inventoried plots, within $20 \mathrm{~m}$ elevation bands centered on each $10 \mathrm{~m}$ elevation steps along the elevation gradient in the study area. The plots were grouped with a hierarchical clustering and the groups were attributed to a vegetation type, according to the classification of Delarze and Gonseth (2008), on the basis of their respective differential species. The curve was fitted with a GAM function. 


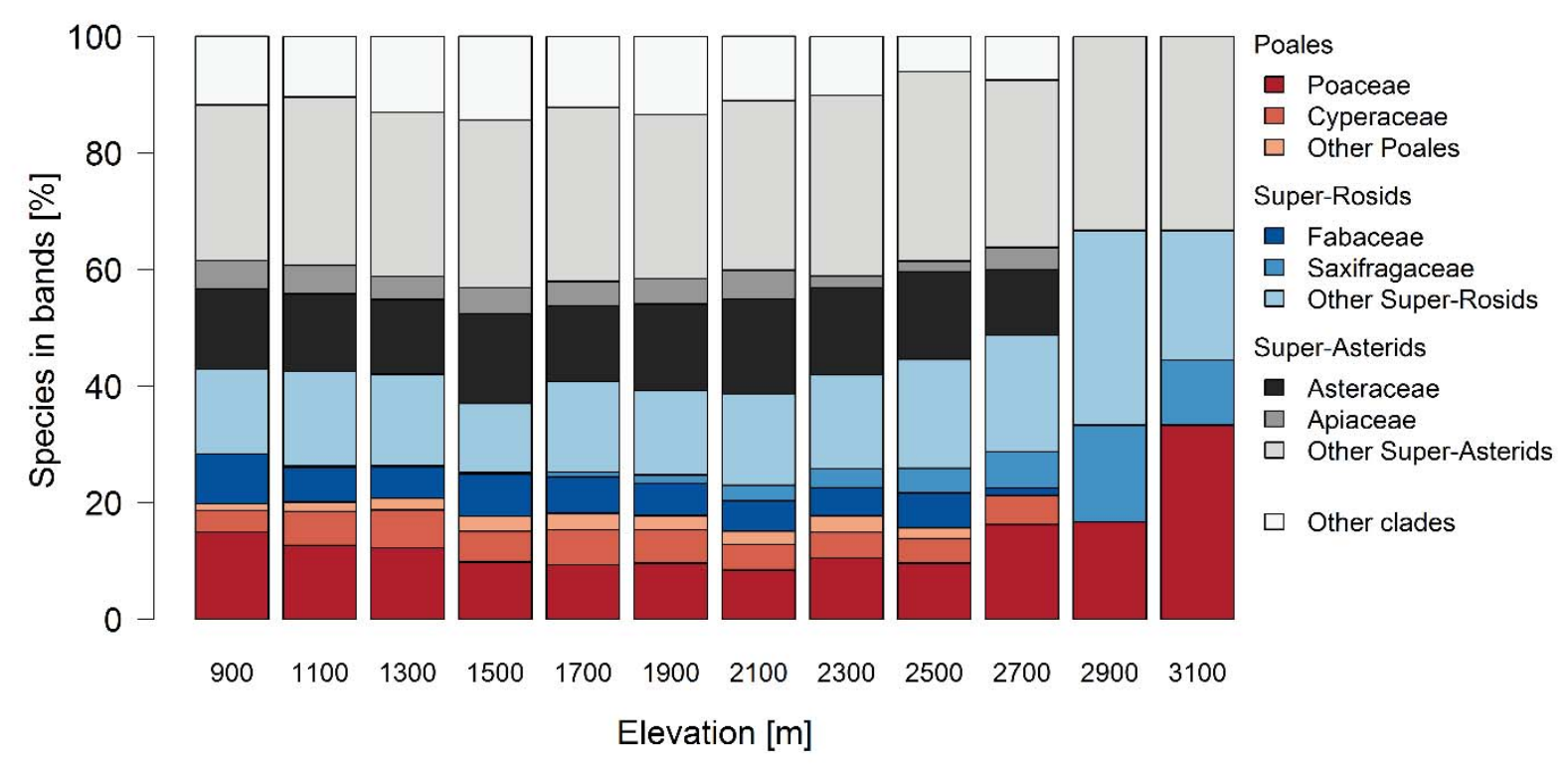

Fig. S4 Proportion of the main vascular plant clades in the species pool (gamma-diversity) in elevation bands of $200 \mathrm{~m}$. The different shades of red-orange correspond to Poales, the blue shades to Super-Rosids and the grey-black shades to Super-Asterids.

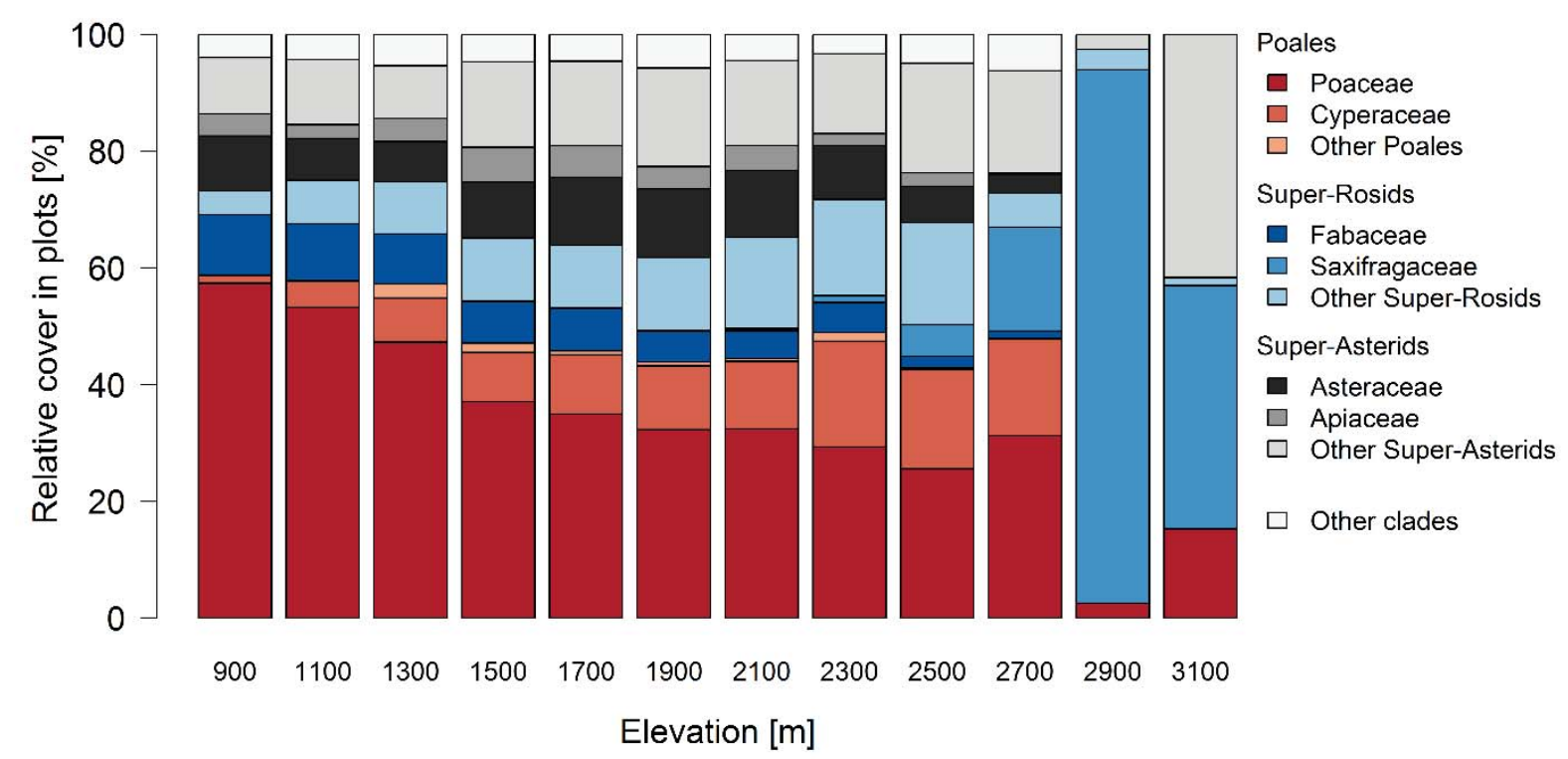

Fig. S5 Mean relative cover (bare soil and rock excluded) of the main vascular plant clades in plant communities in elevation bands of $200 \mathrm{~m}$. See Fig. S5 for the real mean cover of the main vascular plant clades in plant communities when taking in account bare soil and rock. The different shades of red-orange correspond to Poales, the blue shades to Super-Rosids and the grey-black shades to Super-Asterids. 


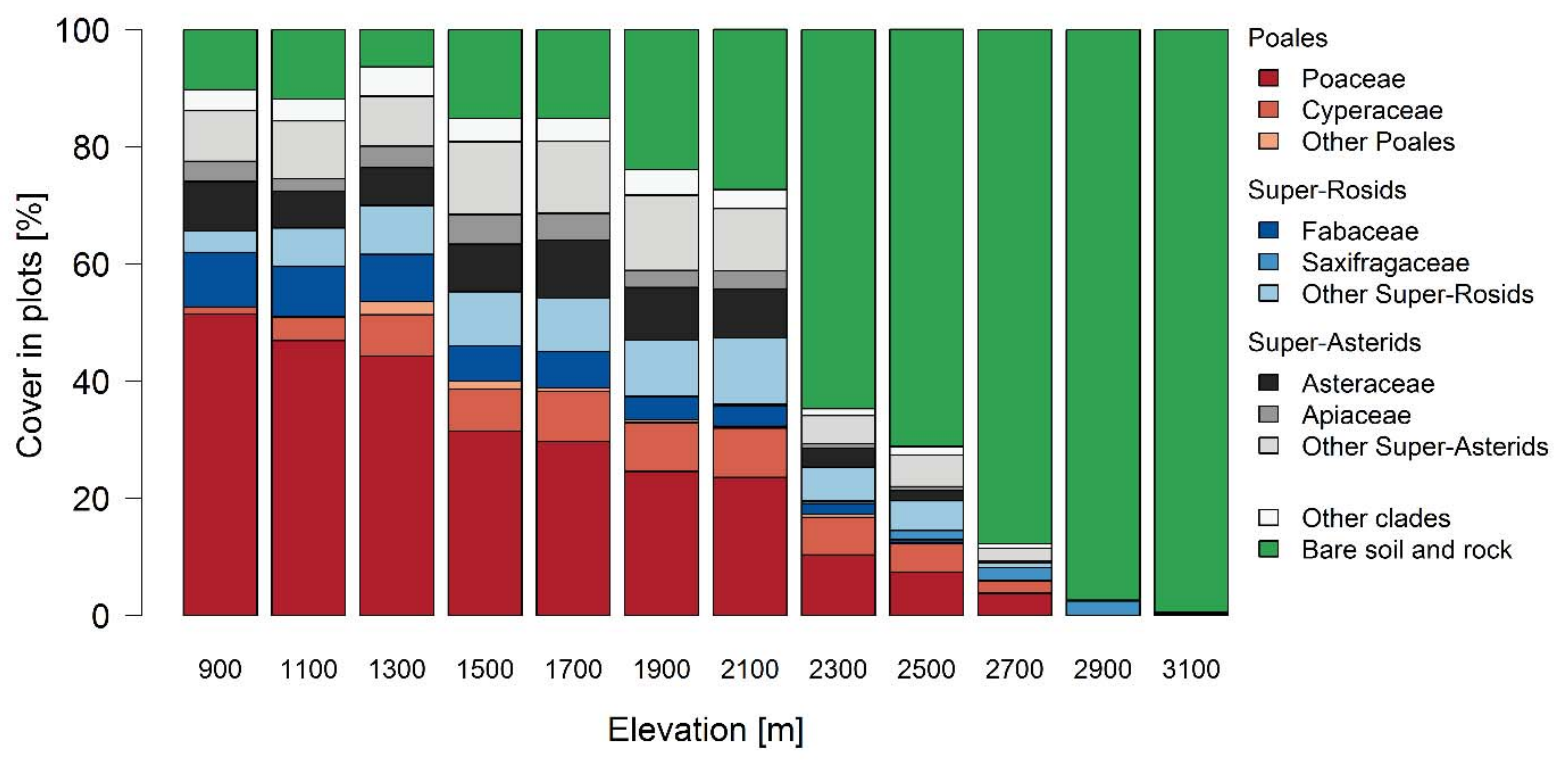

Fig. S6 Mean cover of the main vascular plant clades and cover of bare soil and rock in plant communities in elevation bands of $200 \mathrm{~m}$. The different shades of red-orange correspond to Poales, the blue shades to Super-Rosids and the grey-black shades to Super-Asterids. 
(a)

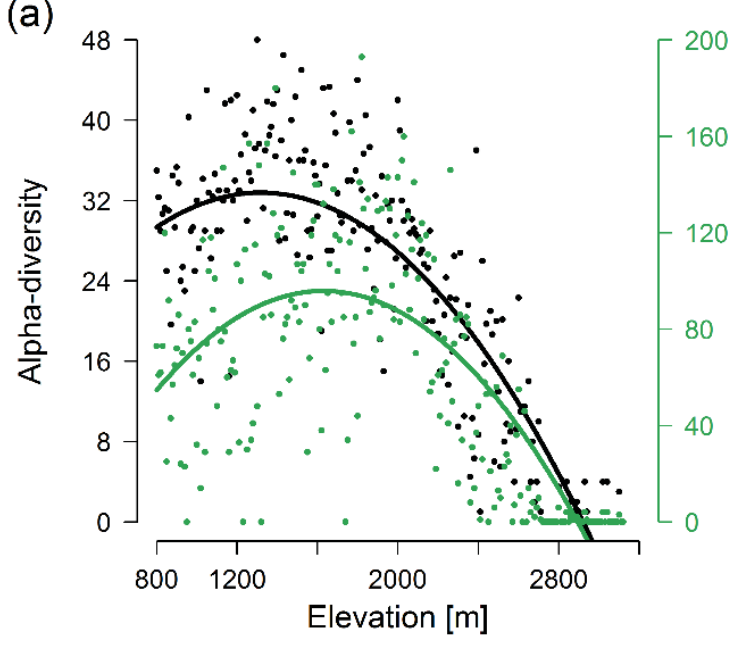

(c)

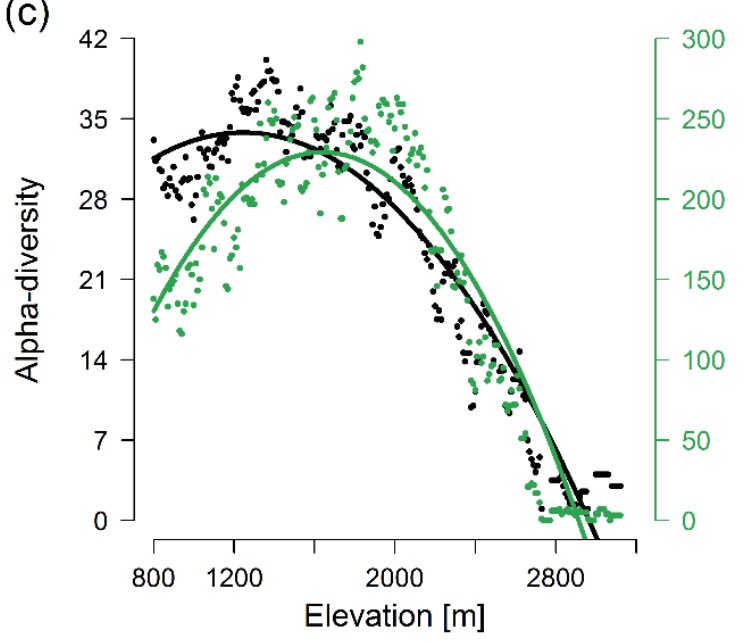

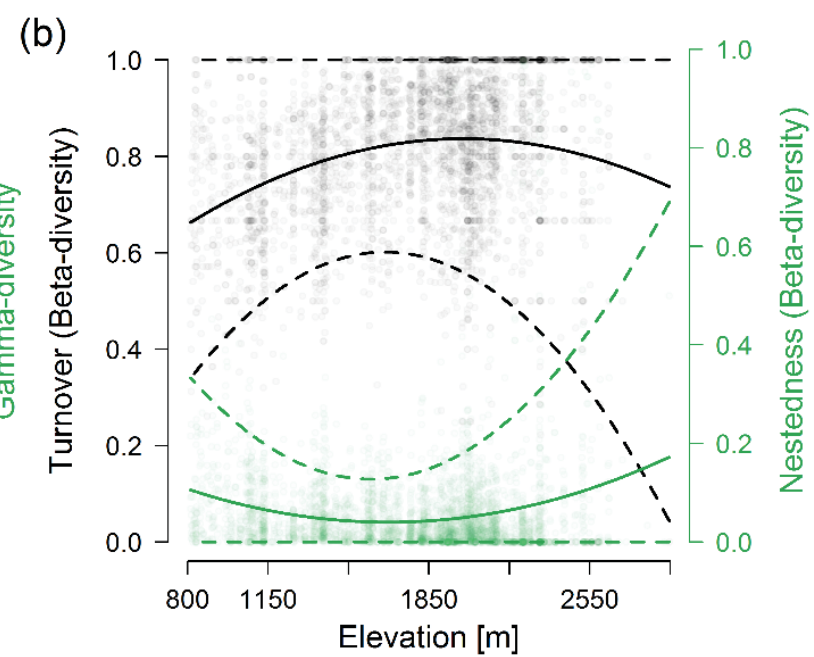

(d)

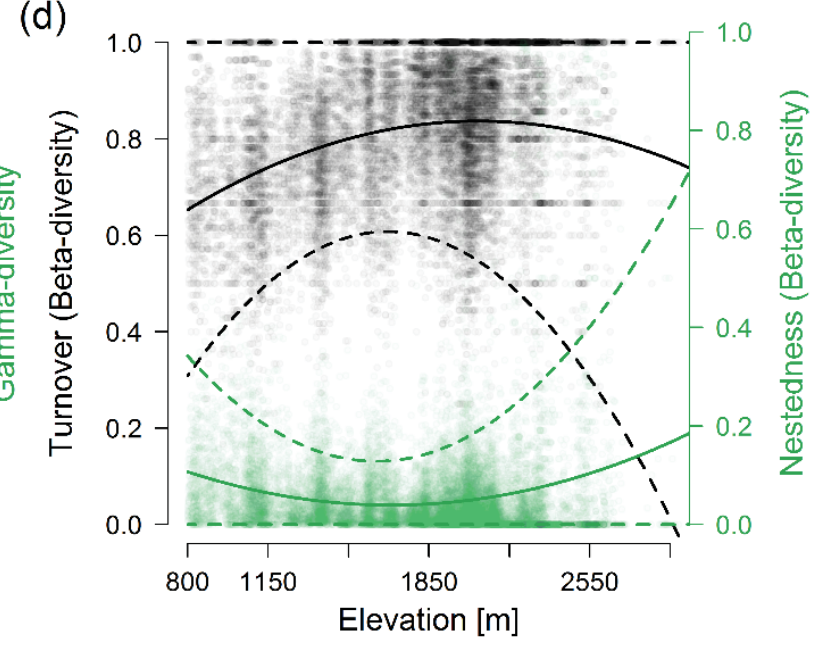

Fig. S7 Diversity changes along the elevation gradient obtained by comparing plant communities of the same elevation (range; $a$ and b: $10 \mathrm{~m}$; $c$ and d: $50 \mathrm{~m}$ ) as a measure of (a and c) mean community diversity (black points; mean alpha-diversity), total species richness (green points; gamma-diversity) and ( $b$ and d) proportion of species turnover (black points; turnover component of beta-diversity) and nestedness (green points; nestedness component of beta-diversity). Curves represent the quadratic relationships. Dashed lines represent the 5 and 95 percentiles. 
(a)

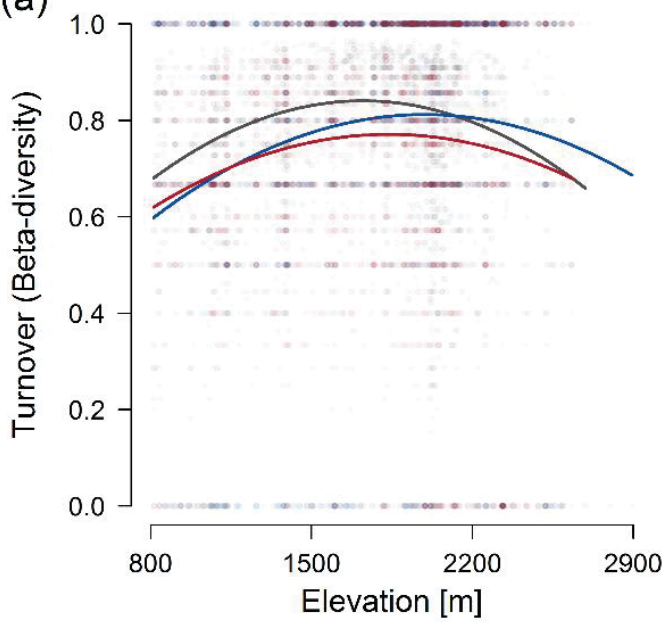

(c)

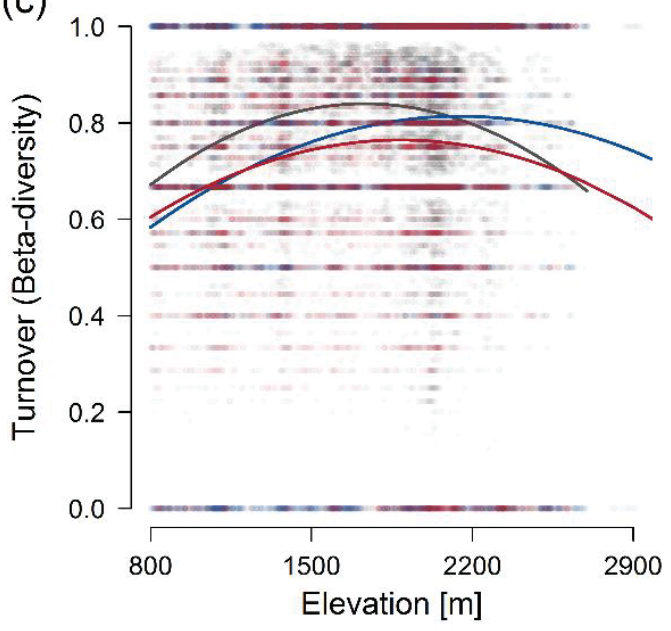

(b)

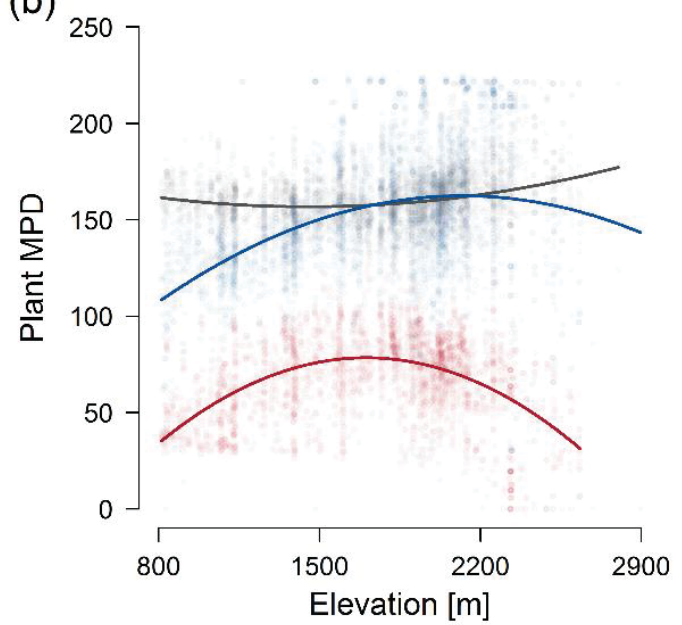

(d)

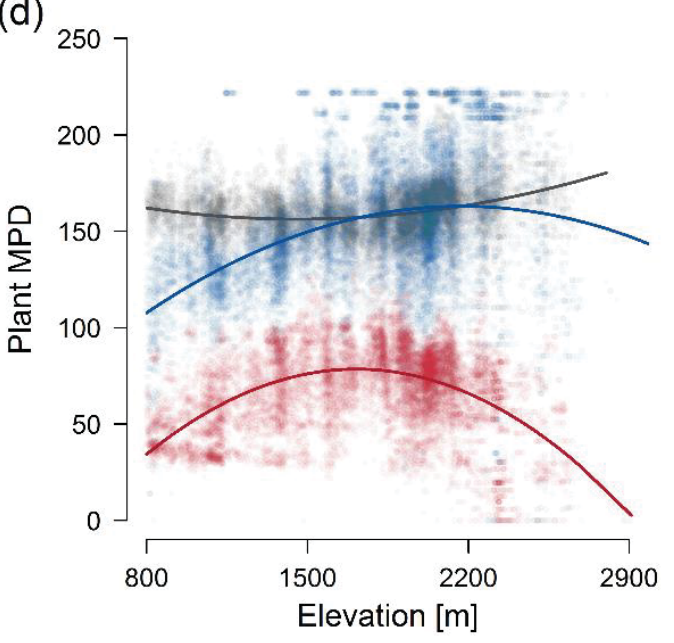

Fig. S8 Relationship between elevation and (a and c) proportion of plant species turnover (turnover component of beta-diversity) and ( $b$ and d) phylogenetic plant relatedness calculated as the mean pairwise distance (MPD) separating taxa in pairs of plant inventories of the same elevation (range; $a$ and b: $10 \mathrm{~m}, \mathrm{c}$ and d: $50 \mathrm{~m}$ ) for Super-Asterids (black points), SuperRosids (blue points) and Poales (red points) clades. Curves represent the quadratic relationships.

\section{References}

Delarze R, Gonseth Y (2008) Guide des milieux naturels de Suisse. Ecologie - Menaces Espèces caractéristiques. Rossolis, Bussigny

Zimmermann NE, Kienast F (1999) Predictive mapping of alpine grasslands in Switzerland: Species versus community approach. J Veg Sci 10:469-482. doi: 10.2307/3237182 